\title{
Manganese Inhalation as a Parkinson Disease Model
}

\author{
José Luis Ordoñez-Librado, Verónica Anaya-Martínez, Ana Luisa Gutierrez-Valdez, \\ Laura Colín-Barenque, Enrique Montiel-Flores, and Maria Rosa Avila-Costa
}

Laboratorio de Neuromorfologia, Facultad de Estudios Superiores Iztacala, UNAM, Avenida de los Barrios 1, Los Reyes Iztacala, 54090 Tlalnepantla, Edo Mex, Mexico

Correspondence should be addressed to Maria Rosa Avila-Costa, nigraizo@unam.mx

Received 16 September 2010; Accepted 13 October 2010

Academic Editor: Yuzuru Imai

Copyright (C 2011 José Luis Ordoñez-Librado et al. This is an open access article distributed under the Creative Commons Attribution License, which permits unrestricted use, distribution, and reproduction in any medium, provided the original work is properly cited.

\begin{abstract}
The present study examines the effects of divalent and trivalent Manganese $\left(\mathrm{Mn}^{2+} / \mathrm{Mn}^{3+}\right)$ mixture inhalation on mice to obtain a novel animal model of Parkinson disease (PD) inducing bilateral and progressive dopaminergic cell death, correlate those alterations with motor disturbances, and determine whether L-DOPA treatment improves the behavior, to ensure that the alterations are of dopaminergic origin. CD-1 male mice inhaled a mixture of Manganese chloride and Manganese acetate, one hour twice a week for five months. Before Mn exposure, animals were trained to perform motor function tests and were evaluated each week after the exposure. By the end of Mn exposure, 10 mice were orally treated with $7.5 \mathrm{mg} / \mathrm{kg} \mathrm{L-DOPA}$. After 5 months of Mn mixture inhalation, striatal dopamine content decreased 71\%, the SNc showed important reduction in the number of TH-immunopositive neurons, mice developed akinesia, postural instability, and action tremor; these motor alterations were reverted with L-DOPA treatment. Our data provide evidence that $\mathrm{Mn}^{2+} / \mathrm{Mn}^{3+}$ mixture inhalation produces similar morphological, neurochemical, and behavioral alterations to those observed in PD providing a useful experimental model for the study of this neurodegenerative disease.
\end{abstract}

\section{Introduction}

Parkinson disease $(\mathrm{PD})$ is a progressive neurodegenerative disorder that affects $1 \%$ of the population over 55 years of age. The pathologic hallmark of the disease is the loss of dopaminergic neurons in the Substantia Nigra pars compacta $(\mathrm{SNc})$ and the presence of intracytoplasmic inclusions named Lewy bodies, formed mainly by $\alpha$-synuclein and ubiquitin. In the striatum, there is a loss of dopamine (DA) and its metabolites homovanillic acid and 3,4-dihydroxyphenylacetate [1-3]. The dopaminergic loss in the striatal spiny neurons is followed by a cascade of events that ultimately changes its structure and the activity of basal ganglia circuits, resulting in the development of PD symptomatology. The main symptoms of the disease are tremor, bradykinesia, hypokinesia, balance, and gait disturbances. The basic process behind the nigrostriatal degeneration still remains unsolved. However, among many other hypothetical degenerative mechanisms, oxidative stress has become an important candidate in producing the neuropathological alterations in PD [3].

Although the etiology of PD is still not fully understood, animal models have provided important clues. On the basis of experimental and clinical findings, PD was the first neurological disease to be modeled and, subsequently, to be treated by neurotransmitter replacement therapy [4]. All PD models are based on the concept that parkinsonian signs are related to dopaminergic nigral cell loss. Several models exhibit many of the characteristic features of the disease; however, none mimics the complex chronic neurodegenerative features of human PD. The 6-hydroxydopamine (6-OHDA) and the 1-methyl-4-phenyl-1,2,3,6tetrahydropyridine (MPTP) are neurotoxins which selectively and rapidly destroy catecholaminergic neurons (within 1-3 days), whereas in humans the PD pathogenesis follows a progressive course over decades.

According to Emborg [5], an ideal animal model can be described by presenting behavioral signs and pathology that 
resemble the disease, including its time course. The closer the similarity of a model is to $\mathrm{PD}$, the higher the predictive validity for clinical efficacy is.

It has been investigated the effects of Manganese (Mn) as a PD model, due to its toxicity (referred to as manganism) shares neurological symptoms with several clinical disorders commonly described as "extrapyramidal motor system dysfunction," and, in particular, idiopathic PD [6-8].

Postmortem studies in humans [9-13] and chronic studies in nonhuman primates [14-18] and rodents [19-22] revealed that $\mathrm{Mn}$ intoxication produces neuropathological changes in the basal ganglia, structures that include the globus pallidus (GP), caudate nucleus and putamen (striatum), and less frequently the substantia nigra (SN) $[12,21$, 23].

The human central nervous system is an important target for Mn intoxication [6-8, 24-27]; its toxicity is targeted to DA-rich brain regions neurons possibly via the dopamine transporter (DAT) [28-31].

In vitro studies indicate that $\mathrm{Mn}$ produces an inhibition of oxidative phosphorylation [32], increasing of reactive oxygen species in synaptosomes [33], and enhances the rate of DA auto-oxidation [34-36], while intrastriatal administration of $\mathrm{Mn}$ leads to impaired energy metabolism, excitotoxic lesions, decreased DA, GABA, and substance P levels $[37,38]$ and accelerate the oxidation of DA [36]. Moreover, it has been reported that unilateral intranigral Mn administration induces ipsilateral turning, while bilateral infusion resulted in akinesia and dystonic posturing of the hind limbs, assuming that those alterations are due to decreasing DA levels [38-40].

The cellular, intracellular, and molecular mechanisms underlying neurotoxicity of $\mathrm{Mn}$ compounds are numerous, as it impacts many biological activities depending on levels and routes of exposure, dosage, age of the exposed individual, and duration of exposure [41].

Great discrepancy exists about Mn-inducing PD, including the specificity of Mn-damaging GP or SN [7, 17, 42]. Olanow [43], Perl and Olanow [44], Lucchini et al. [45], Guilarte [46], and others suggest that PD preferentially damages DA neurons in the SN, while Mn preferentially accumulates within and damages GP and striatum, while sparing the nigrostriatal system. According to Calne et al. [7], Lu et al. [47], Cersosimo and Koller [48], Aschner et al. $[49,50]$, and others, the most important among these differences is the lack of clinical response to L-DOPA.

However, studies have reported seemingly conflicting results on the dopaminergic effects of Mn (see Gwiazda et al. [51] and Guilarte [46] for review), including decrease $[14,21,27,40,52-56]$, increase $[19,57]$, both, increase and decrease [20], or no change $[25,42,58]$ in nigral or striatal DA concentrations in Mn-treated animals, possibly reflecting effects of the different exposure regimens on DA outcomes. These discrepancies may well reflect differences in exposure route, magnitude, duration, Mn concentration or compound, age of the experimental animals, and so forth between studies, though they also demonstrate the complexity of $\mathrm{Mn}$ toxicity and suggest that the factors contributing to its toxicity are not well understood.
It seems that at lower doses, Mn increased DA and its metabolite levels, while the opposite effect was seen at higher doses $[20,59]$. Likewise, it has been suggested that higher concentrations of Mn may significantly accelerate the oxidation of DA and other catecholamines, which concurrently amplify the formation of reactive oxygen species $[34,36,60]$.

It has been reported that divalent and trivalent manganese may be transported into the brain across the bloodbrain and the blood-CSF barriers [61, 62]. Divalent Mn can be transported into brain capillary endothelial cells and choroidal epithelial cells via undefined divalent metal transporter DMT- 1, DCT-1, or nramp-2 [63]. In the brain, it is known that $\mathrm{SN}$ and striatum are regions rich in DMT-1 [64]. On the other hand, trivalent Mn bound to transferrin is transported across the brain barriers via the receptor-mediated endocytosis [62]. Mn is then released from the complex into the endothelial cell by endosomal acidification [50]. Mn released within the endothelial cells is subsequently transferred to the abluminal cell surface for release into the extracellular fluid. Mn delivered to brainderived transferrin for extracellular transport, subsequently is taken up by neurons, oligodendrocytes, and astrocytes for usage and storage [65]. In the mitochondria, it has been demonstrated that $\mathrm{Mn}$ inhibits complex I thereby leading to altered oxidative phosphorylation, and it seems that $\mathrm{Mn}^{3+}$ is more potent at inhibiting complex I than $\mathrm{Mn}^{2+}$ [66-68] and accelerates the oxidation of ferrous iron. Low micromolar concentrations of $\mathrm{Mn}^{3+}$ are sufficient to trigger an immediate oxidation of ferrous iron, whereas divalent $\mathrm{Mn}$ at concentrations of 100 -fold higher did not promote the conversion of ferrous to ferric [69].

The enhanced ability of trivalent Mn to induce oxidative stress has been confirmed in rats given either manganese chloride $\left[\mathrm{MnCl}_{2}\left(\mathrm{Mn}^{2+}\right)\right]$ or manganese acetate $\left[\mathrm{Mn}(\mathrm{OAc})_{3}\left(\mathrm{Mn}^{3+}\right)\right]$ [67]; these authors report that $\mathrm{MnCl}_{2}$ $(1-1000 \mu \mathrm{M})$ produced dose-dependent increases of reactive oxygen species in striatum whereas MnOAc produced similar increases at much lower concentrations $(1-100 \mu \mathrm{M})$. Thus, the valence of $\mathrm{Mn}$ and its metabolism seem to influence its toxicity.

Therefore, the pro-oxidant activity of $\mathrm{Mn}^{2+}$ is dependent on trace amounts of $\mathrm{Mn}^{3+}$, which may facilitate a small portion of $\mathrm{Mn}^{2+}$ to oxidize to $\mathrm{Mn}^{3+}$. This synergistic relationship between $\mathrm{Mn}^{2+}$ and $\mathrm{Mn}^{3+}$, results in continuous redox cycling [69]. These findings lead us to hypothesize that if the animals are exposed to the mixture of $\mathrm{Mn}^{2+} / \mathrm{Mn}^{3+}$, it would be possible to find cell and behavioral alterations resembling those found in PD.

Since it has been postulated that $\mathrm{Mn}^{3+}$ is more potent in producing oxidative stress and $\mathrm{Mn}^{2+}$ needs the presence of $\mathrm{Mn}^{3+}$ to reach oxidation and that there is a synergy between the two Mn states, the current study investigates the effects of $\mathrm{Mn}^{2+} / \mathrm{Mn}^{3+}$ mixture inhalation on mice to obtain a novel animal model of PD inducing bilateral and progressive cell death in the SNc and correlating those alterations with motor disturbances. As a next step, we sought to determine if after $\mathrm{Mn}$ inhalation the movement alterations improve with $\mathrm{L}^{-}$ DOPA treatment in order to ensure that the alterations origin is dopaminergic. 


\section{Experimental Procedures}

Fourty-five CD-1 male mice weighing $33 \pm 2 \mathrm{~g}$ were individually housed in hanging plastic cages under controlled light conditions ( $12 \mathrm{~h}$ light $/ \mathrm{h}$ dark regime) and fed with Purina Rodent Chow and water ad libitum. Body weight was recorded daily. The experimental protocol was conduced in accordance with the Animal Act of 1986 for Scientific Procedures. All efforts were made to minimize the number of animals used and their suffering.

2.1. Motor Behavior. Prior to Mn inhalation, all the animals were trained in the reaching task and beam-walking test to evaluate motor performance. Training and testing were performed during the lighted portion of the cycle, at the same hour every time. For the reaching task mice were food deprived to $90 \%$ of normal body weight and received measured amounts of food once a day to maintain body weight and deprivation state. The motor behavior tests were performed during the days the animals did not inhale. Each mouse was tested once a week, a different day for each test. Two observers blind to the mice exposed or control status perform all behavioral assessments.

2.2. Single-Pellet Reaching Task. The plexiglas reaching box was $19.5 \mathrm{~cm}$ long, $8 \mathrm{~cm}$ wide, and $20 \mathrm{~cm}$ high. A $1-\mathrm{cm}$ wide vertical slit ran up the front of the box. A $0.2 \mathrm{~cm}$ thick plastic shelf $(8.3 \mathrm{~cm}$ long and $3.8 \mathrm{~cm}$ wide $)$ was mounted $1.1 \mathrm{~cm}$ from the floor on the front of the box. Before training, animals were food deprived for $24 \mathrm{hr}$. Afterward, they received a restricted diet of $\sim 10 \mathrm{gm} / \mathrm{kg}$ body weight adjusted to keep their weight constant. Twenty milligram food pellets were placed in indentations spaced $1 \mathrm{~cm}$ away from the slit and centered on its edges. Animals were habituated for 1 week by placing them in the cages for 10 minutes. Pellets were initially available on the cage floor and within tongue distance on the shelf. Pellets were gradually removed from the floor and placed farther away on the shelf $(1 \mathrm{~cm})$ until the mouse were forced to reach to retrieve the food. As the animal pronates the paw medially, this placement allows the mouse to obtain the pellet with a paw and not with the tongue. Mice were individually trained and allowed to reach with their preferred forelimb for food pellets [70]. Each animal reached for 20 pellets each day during the testing period. If an animal reached through the slot and obtained a food pellet, the reach was scored as a success. If an animal knocked the food away or dropped the food after grasping it, the reach was scored as a miss [71]. Qualitative assessment consisted in analyzing the "reaching performance," the postural shift and impairments in limb extension, aim, and supination-pronation of the paw during grasping, and release of the pellet into the mouth.

2.3. Beam Walking Test. The additional test to measure motor coordination of mice was assessed by measuring the ability of the animals to traverse a narrow beam $(3 \mathrm{~mm})$ to reach an enclosed safety platform [72]. The apparatus is constructed by elevating surface of a $10 \times 100 \mathrm{~cm} \times 3 \mathrm{~mm}$ wooden beam $75 \mathrm{~cm}$ above the floor with wooden supports with $15^{\circ}$ inclination. A goal box is located at one end of the beam. During training, animals were placed at the beginning of the beam with no inclination and they were trained over 4 days ( 4 trials per day). Once the animals crossed the beam in a 20 seconds interval, they received two more consecutive trials with the inclined beam. Animals were allowed up to 60 sec to traverse the beam. The latency to traverse beam was recorded for each trial.

2.4. Video Recording. Performance during single pellet reaching and beam walking tests was video recorded using a Sony camcorder (1000th of a second shutter speed). The camera was positioned orthogonally to the reaching box such that the animal behavior was filmed from the front. Representative still frames were captured from digital video recordings with the video editing software Final Cut Pro. Pictures were cropped and adjusted for color and brightness contrast in Adobe Photoshop V.11.0.2 but were not altered in any other way.

Neurological Evaluation. Tremor and bradykinesia (slowed ability to start and continue movements and impaired ability to adjust body's position) were evaluated by inspection of Mn-exposed compared with control mice during the performance of the two tests.

\subsection{Manganese Inhalation}

2.5.1. Pilot Study. A pilot study was performed (5 control and $5 \mathrm{Mn}$ exposure mice) with 0.02 and $0.03 \mathrm{M}$ Manganese chloride $\left(\mathrm{MnCl}_{2}\right)$ and 0.01 and $0.02 \mathrm{M}$ Manganese acetate $\left[\mathrm{Mn}(\mathrm{OAc})_{3}\right]$ (Sigma Chemical Co Mexico), and after 6, 8, 10, and 12 inhalations by light microscopy, some changes were observed in SNc tyroxine hidroxylase (TH) immunoreactive neurons. However, the loss of $\mathrm{TH}$-immunostained cells were not enough to observe behavioral alterations (data not shown). Thus, higher doses were used; the mixture of $0.04 \mathrm{M} \mathrm{MnCl}_{2}$ and $0.02 \mathrm{M} \mathrm{Mn}(\mathrm{OAc})_{3}$, and knowing that the half-life of $\mathrm{Mn}$ is about $30-48 \mathrm{~h}$ and scarce information is available about inhalation, we planned a twice a week exposure protocol.

Inhalations were performed as described by Avila-Costa et al. [73]. Twenty animals were placed in an acrylic chamber inhaling $0.04 \mathrm{M} \mathrm{MnCl}_{2}$ and $0.02 \mathrm{M} \mathrm{Mn}(\mathrm{OAc})_{3}$ (Sigma Aldrich, Co. Mexico) $1 \mathrm{~h}$ twice a week for five months. Fifteen control mice inhaled only the vehicle-deionized waterfor the same period. Inhalations were performed in closed acrylic boxes $(35 \mathrm{~cm}$ wide $\times 44 \mathrm{~cm}$ long and $20 \mathrm{~cm}$ high) connected to an ultranebulizer (Shinmed, Taiwan), with $101 /$ min continuous flux. The ultranebulizer is designed to produce droplets in a $0.5-5 \mu \mathrm{m}$ range. A trap for the vapor was located in the opposite side with a solution of sodium bicarbonate to precipitate the remaining metal. During exposures, animals were continuously visually monitored for respiration rate, depth, and regularity. The exposure system was continuously monitored for temperature, oxygen level, and $\mathrm{Mn}$ concentration. 


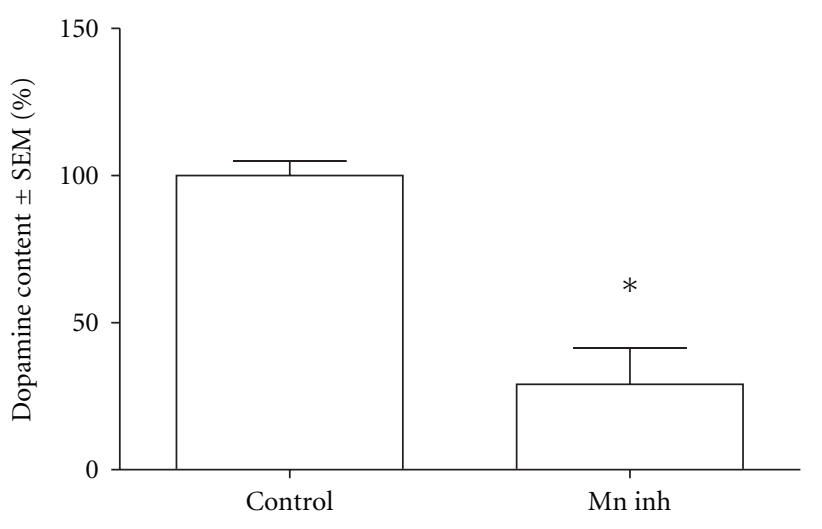

Figure 1: Decrease of dopamine content in the striatum after 5 months of $\mathrm{Mn}$ inhalation compared to controls. Contents are expressed as percentages, which were in $\mathrm{pg} / \mathrm{micro}$ gram of protein $\left({ }^{*} P<.001\right.$ versus control group by one-way ANOVA with post-hoc comparisons).

After 5 months (40 inhalations), when important motor alterations were observed, 20 mice were sacrificed ( 10 control and $10 \mathrm{Mn}$-exposed), anesthetized with sodium pentobarbital lethal dose, and perfused via aorta with phosphate buffer saline ( $0.1 \mathrm{M}$ p.H. 7.4) containing $2 \%$ glutaraldehyde and $2 \%$ paraformaldehyde. The brain was removed and placed in fixative solution for $2 \mathrm{hr}$ and processed for $\mathrm{TH}$ inmunocytochemistry (5 control and $5 \mathrm{Mn}$-exposed brains).

Afterwards, the remaining mice continued inhaling $\mathrm{Mn}$. Five were orally treated with $7.5 \mathrm{mg} / \mathrm{kg}$ L-DOPA (Sinemet [Carbidopa-L-DOPA 25/250]) daily for two months, 5 were kept for the same time without treatment, and 5 control were kept for the same time and then sacrificed for further analysis; the motor performance was evaluated weekly.

2.6. Immunocytochemistry. Coronal sections $(50 \mu \mathrm{m})$ were obtained on a vibrating microtome through the mesencephalon for immunocytochemistry. Tyrosine hydroxilase (Chemicon International, Inc. CA, USA, $1: 1000$ ) immunostaining with the $\mathrm{ABC}$ detection method (Vector Lab MI, USA) was performed for light microscopic analysis. The analysis was conducted with a computer-assisted system (Image-Pro Plus, Media Cybernetics, L.P. Del Mar, CA, USA) connected by a CCD camera to Optiphot 2 microscope (Nikon, Japan). The number of TH-positive neurons was counted in $1500 \mu \mathrm{m}^{2}$ from 14 mesencephalic sections of each animal, the cell count included SNc and ventral tegmental area (VTA) [73].

2.7. Dopamine Concentrations. Striatal dopamine contents were obtained after 5 months of $\mathrm{Mn}$ inhalation as described elsewhere [74]. Briefly, 5 control and $5 \mathrm{Mn}$-exposed mice were anesthetized and decapitated, and using a stereoscopic microscope the striatum was dissected. The tissue was homogenized in perchloric acid utilizing $100 \mu \mathrm{l}$ per brain. Homogenates were centrifuged (300 PSI, 2 min, airfuge centrifuge, Beckman; Fullerton, CA, USA), and the supernatants were filtered $(0.22-\mu \mathrm{m}$ membranes, Millipore; Bedford,
MA, USA). The pellets were resuspended $(120 \mu \mathrm{l}$ of $0.1 \mathrm{M}$ $\mathrm{NaOH}$ ) and used for protein determination as reported by Bradford [75]. Dopamine content in $10 \mu \mathrm{l}$ of supernatant was determined using a reverse phase HPLC system coupled to an electrochemical detector (BAS; West Lafayette, IN, USA). Chromatograms were analyzed using the Peak II integration software (SRI Instruments; Torrance, CA, USA). The DA content was expressed as $\mathrm{pg} / \mu \mathrm{g}$ protein.

2.8. $\mathrm{Mn}$ Concentrations. The concentrations of $\mathrm{Mn}$ in the chamber were quantified as follows. A filter was positioned at the outlet of the ultranebulizer during the whole inhalation time at a flow rate of $10 \mathrm{l} / \mathrm{min}$. After each exposure, the filter was removed and weighed; the element was quantified using a graphite furnace atomic absorption spectrometer (Perkin Elmer Mod. 3110, CT, USA). Six filters for each inhalation were evaluated [76]. Mn content in serum was also measured by graphite furnace atomic absorption spectrometry at the end of the experiment.

2.9. Statistical Analysis. One-way ANOVA was used to analyze the number of TH-immunopositive cells and behavioral data. Group differences were considered statistically significant at $P<.05$. When appropriate, post-hoc comparisons were made with the Tukey test. All analyses were conducted with SigmaPlot 11 (SYSTAT Software).

\section{Results}

After 7 months of exposure neither clinical alterations nor significant weight changes were detected in the exposed animals compared with controls.

3.1. Manganese Concentrations. The average Mn concentration measured in the filters of the chamber was of $2676 \mu \mathrm{g} / \mathrm{m}^{3}$ during the whole experiment. The average Mn concentration in serum of exposed animals was of $30 \pm 5 \mu \mathrm{g} / \mathrm{l}$; control mice serum concentration of $\mathrm{Mn}$ was of $0.05-0.12 \mu \mathrm{g} / \mathrm{l}$.

Figure 1 shows the change in dopamine content determined in the striatum after 5 months of $\mathrm{Mn}$ inhalation compared to controls. The average content in the control mice was $96.545 \pm 4.8820$ and $28.008 \pm 12.4500 \mathrm{pg} / \mu \mathrm{g}$ of protein for Mn-exposed mice; hence, dopamine content declines $71 \%$.

3.2. Single-Pellet Reaching Task. The task involves execution of a complex motor sequence, starting with sniffing a food pellet at the front of the reaching chamber, lifting the arm, adjusting posture to project the arm through a narrow slot toward the pellet, and grasping the target (Figure 2).

Animals were presented with 20 food pellets. Figure 3 shows the results of successful reaches over the course of the experiment. Repeated-measures ANOVA confirmed a significant effect of $\mathrm{Mn}$-exposed group since $8 \mathrm{Mn}$-inhalations $(P<.001)$. All animals were comparable in their ability to retrieve pellets before $\mathrm{Mn}$ inhalation, but the Mn exposure 

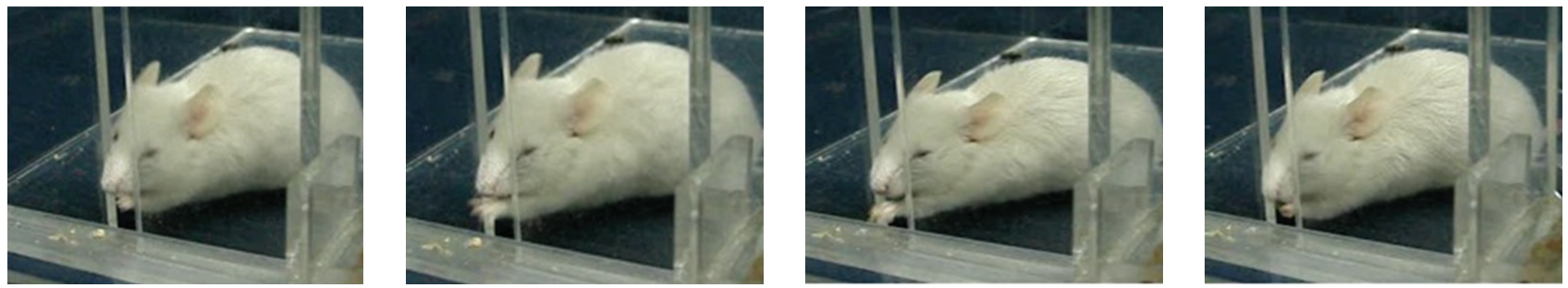

FIGURE 2: Representative still frames of a control mouse captured during limb transport and limb withdrawal. The control animals advanced their forelimb through the slot and extended their digits, and they also supinated their paw to present the food to the mouth and extended their digits to release the food into the mouth (see text for detailed description.)

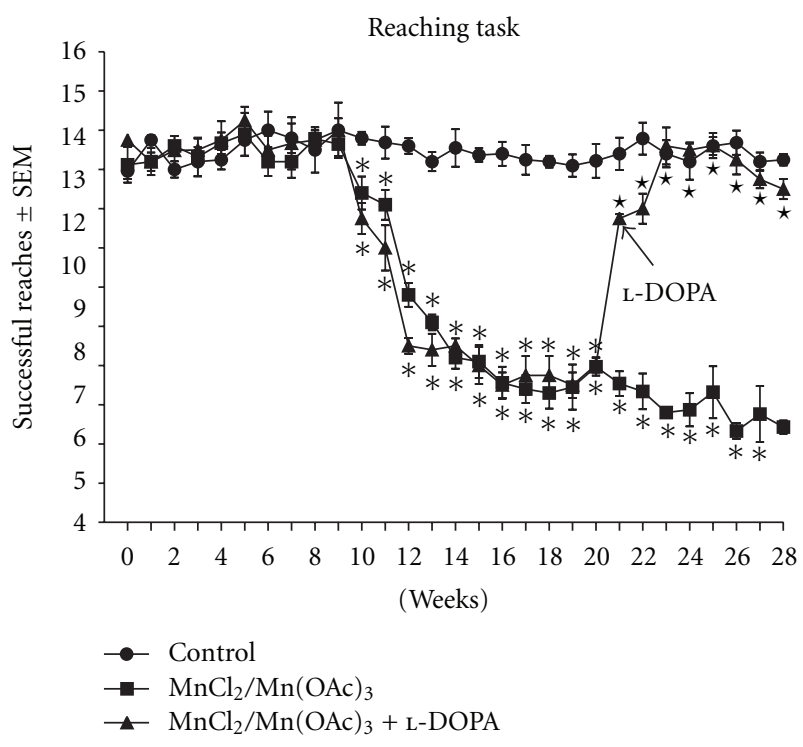

FIgURE 3: Reaching success (number of pellets obtained out of 20; mean \pm SEM) by control, Mn exposed and Mn exposed + L-DOPA treatment mice in the single-pellet task before and after inhalation and after L-DOPA treatment. Note that the Mn-exposed group is impaired since 8 week and the L-DOPA treatment fully reverses the alterations $\left({ }^{*} P<.001\right.$ versus control group; ${ }^{\star} P<.001$ between L-DOPA treatment group versus Mn exposed group).

resulted in a marked impairment in both number of successful retrievals $(P<.001)$ and accuracy; however, when $\mathrm{L}-$ DOPA treatment starts the mice improve their performance when comparing to the nontreated ones, resembling the control mice execution $(P<.001)$. Control animals remained consistent throughout the duration of the experiment and performed significantly better than Mn-exposed animals at all time points (Figures 2 and 3 ).

Qualitative assessment resulted in a postural shift and impairments in limb extension (resulting in many shortened reaches), aim, and supination-pronation of the paw during grasping and release of the pellet into the mouth (Figures 4(a)-4(d)). Mice displayed abnormal movements when retrieving the pellet after $\mathrm{Mn}$ exposure. The paw is often fully pronated and moves either laterally (from the side) over the pellet (Figures 4(b) and 4(c)), or the mouse slaps at the pellet from above. Several animals from Mn-exposed group exhibited such motor abnormalities that persisted for the duration of the experiment.

The Mn-exposed mice are often unable to properly close the digits around the pellet and drag it to the slot without lifting the paw. Mice also fail to supinate the paw completely and place the snout into the slot to retrieve the pellet with the tongue. When the paw is withdrawn through the slot, Mn mice frequently rotate the body and "chase" the pellet with the snout instead of opening the digits and placing the pellet into the mouth. The nonreaching limb is seldom raised for support when retrieving the pellet. Post-hoc tests on the group effect indicated that at more $\mathrm{Mn}$ exposure success scores were significantly poorer (Figure 3 ). These conditions remarkably improve with L-DOPA treatment (Figures 4(e)$4(\mathrm{~h})$ ); the treated mice adjust their posture and project the arm toward the pellet, supinate and pronate the paw to obtain the pellet, close their digits, and drag the food to the snout; their motor performance was comparable to control mice (Figure 3).

3.3. Beam-Walking Test. We further tested Mn-exposed mice for possible alterations in motor activities using a beam traversal task. On the last day of testing before Mn inhalation, there was no significant difference between the latencies in completing the test for the controls $(7.2 \pm 6.9 \mathrm{sec})$ and the Mn-treated subjects $(7.8 \pm 3.1 \mathrm{sec}$ ) (ANOVA test; $P>.001)$. Throughout the course of the experiment, none of the subjects fell from the beam.

Figure 5 illustrates the mean numbers of total time to cross the beam. Mn-exposed mice were observed to have a significant decrease in the duration to cross the beam after 2,4,6, and $8 \mathrm{Mn}$-inhalations suggesting hyperactivity; afterwards have a significant increase in the time to cross and a significant potentiation of freeze time (data not shown), compared with control mice. In addition, animals were also noted to exhibit hind-limb weakness, delayed motor initiative (akinesia), postural instability, and action tremor. L-DOPA treatment reverted these motor alterations.

\subsection{TH-Immunocytochemistry}

3.4.1. Pilot Study. The mean number of TH-positive neurons on the control SNc was 145 neurons (Figures 6 and 7(a)). In the $0.02 \mathrm{M} \mathrm{MnCl}_{2}$-inhaled animals, $\mathrm{TH}$-positive neurons in the SNc were reduced by $4.8-33 \%$ (138 and 98 neurons 


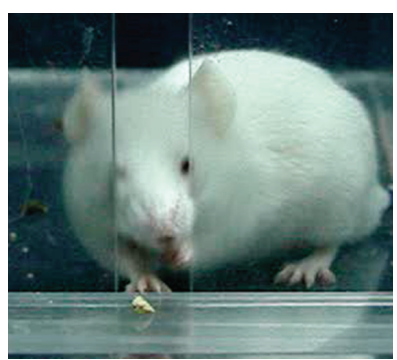

(a)

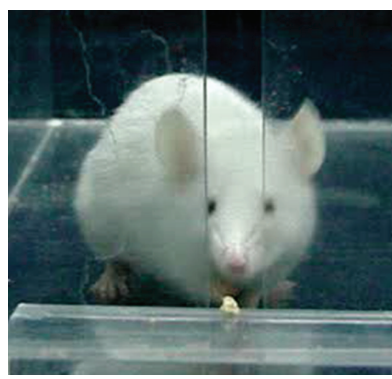

(e)

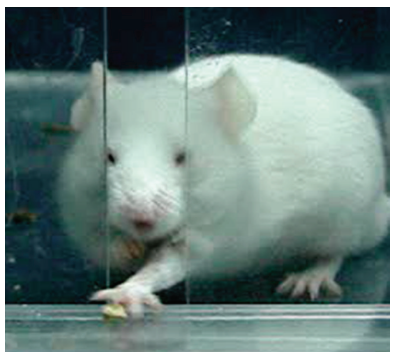

(b)

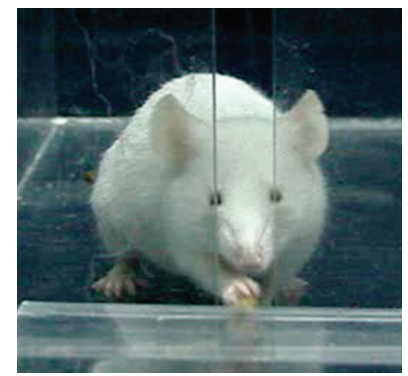

(f)

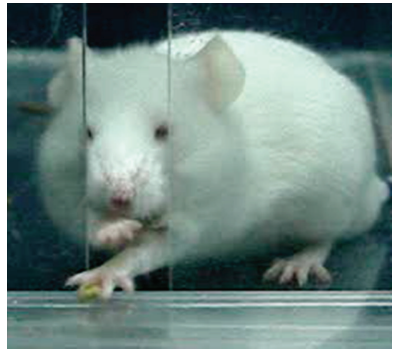

(c)

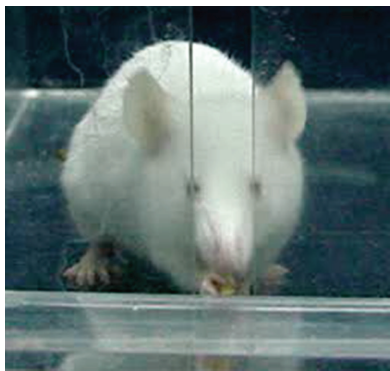

(g)

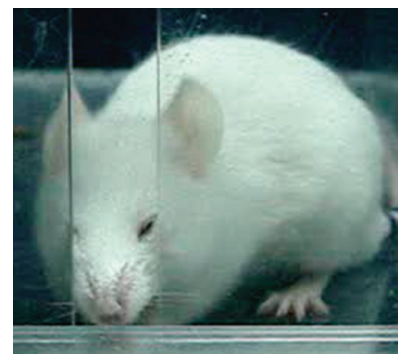

(d)

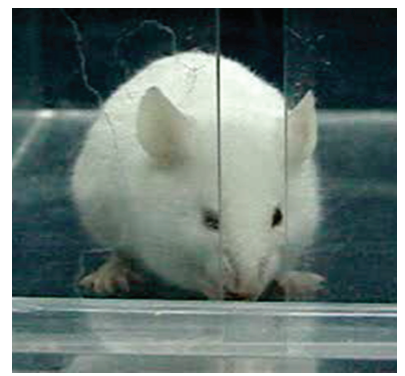

(h)

FIgURE 4: Representative still frames of a Mn-inhaled mouse (a-d) and Mn-inhaled mouse + L-DOPA treatment (e-h). In frames (a)-(d), the mouse showed impairments using extreme postural adjustments advancing the limb diagonally through the slot making many short attempts rather than aligning the limb with the midline of the body. The digits are concurrently adducted. The paw comes in from the side or slaps laterally, and digits do not contact the food pellet. The mouse is dragging its limb through the slot and dropping the pellet to the floor cage chasing the food with the tongue rather than fully pronating the paw and supinating it to present the food to the mouth. In contrast, in frames (e)-(h), the effect of L-DOPA treatment is evident, and the mouse adjusts its posture, directs the arm to the food pellet, and closes its digits to obtain it correctly.

resp. after 6 and 12 inhalations (Figures 6(a) and 7(b)); in the $0.03 \mathrm{M} \mathrm{MnCl}_{2}$-inhaled mice, TH-positive neurons in the SNc were reduced by $11.03-38.6 \%$ ( 129 and 87 neurons resp. after 6 and 12 inhalations (Figures 6(c) and 7(c)); in the $0.01 \mathrm{M} \mathrm{Mn}(\mathrm{OAc})_{3}$-inhaled mice the reduction was from 20 to $44.8 \%$ (116 neurons after 6 inhalations and 80 neurons after 12 inhalations (Figures 6(b) and 7(d)), and in the $0.02 \mathrm{M} \mathrm{Mn}(\mathrm{OAc})_{3}$-inhaled mice the reduction was from 37.9 to $55.1 \%$ (90 neurons after 6 inhalations and 65 neurons after 12 inhalations (Figures 6(d) and 7(e))). Despite these reduction, after 10 inhalations in both cases the neuronal loss reached a plateau and there were no evident behavioral alterations. Hence, we decided to use higher doses and mix both compounds; afterwards we found glaring cell reduction (Figure $7(\mathrm{f})$ ) and motor alterations described above.

\section{5. $\mathrm{MnCl}_{2} / \mathrm{Mn}(\mathrm{OAc})_{3}$ Mixture. After $40 \mathrm{MnCl}_{2} / \mathrm{Mn}(\mathrm{OAc})_{3}$ -} inhalations, a significant loss of the TH-positive neurons in the SNc was observed $(67.58 \%)$ compared with the control group. However, the number and integrity of the TH-positive neurons in the VTA were not significantly affected by Mninhalation (7.6\%) (Figures 8 and 9 ).

\section{Discussion}

This study examined the premise that exposure to $\mathrm{MnCl}_{2}$ $/ \mathrm{Mn}(\mathrm{OAc})_{3}$, when combined, produces additive or even synergistic effects by impacting the DA nigrostriatal system by reducing TH cell counts in the SNc but not in the VTA and decreasing dopamine striatal concentrations. We found considerable hyperactivity immediately after the first inhalations (2-8 inhalations) and afterwards, evident reduction and alterations in locomotor activity, and the motor alterations improve drastically after L-DOPA treatment.

\subsection{Motor Behavior Alterations}

4.1.1. Single-Pellet Reaching Task. The single-pellet task examined both gross ability to retrieve pellets and reaching accuracy, which is more sensitive to subtle impairments and compensatory reaching strategies that may not be detected by other motor tests [77].

Detailed analyses of skilled limb movements, such as the reach-to-grasp movement, show very similar motor components in humans and in rodents [78, 79]. An analysis of the movements used by the rodents indicates that a reach consists of postural adjustments that result in the body being supported by the diagonal couplet of the hind limb ipsilateral to the reaching forelimb and its opposite forelimb. This postural strategy allows the body to shift forward and backward and so aid limb advancement and withdrawal. The reaching movement itself consists of a number of movement subcomponents that include aiming the limb, pronating the paw over the food in order to grasp, and supinating 


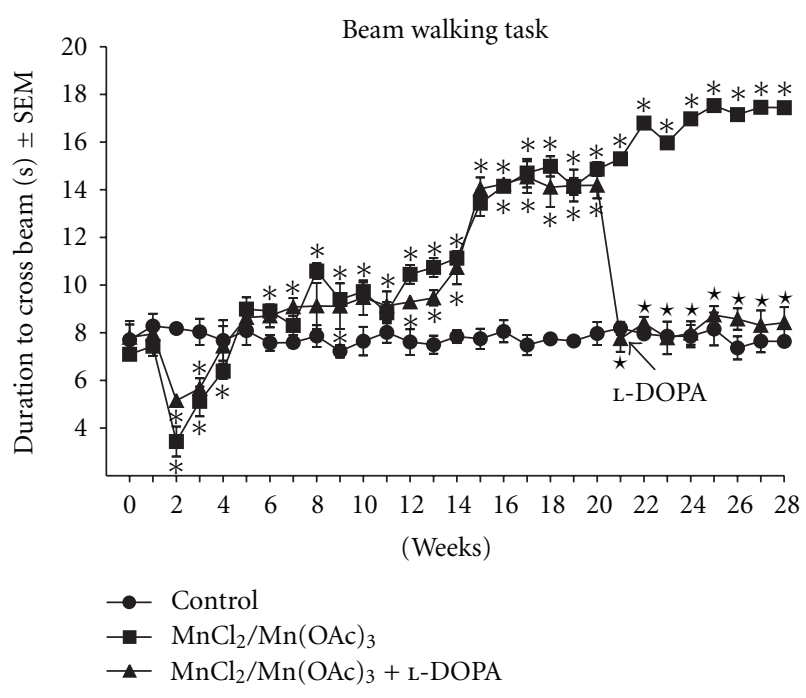

Figure 5: Mean latencies to cross the beam $( \pm$ SEM $)$ before and after Mn-inhalation and after L-DOPA treatment. Note that after 2, 4, 6, and $8 \mathrm{Mn}$-inhalations the mice significantly decrease the duration to cross the beam, and afterwards showed a significant increase in duration to transverse the beam compared to controls. However, when the mice received the L-DOPA treatment the time was reduced drastically resembling the values of the control group $\left({ }^{*} P<.001\right.$ versus control group; ${ }^{\star} P<.001$ between L-DOPA treatment group versus Mn exposed group).

the paw as it is withdrawn so that the food can be presented to the mouth. Humans with PD are often described as having poor manual dexterity that worsens as the disease progresses [80, 81]. They experience difficulties executing tasks requiring unilateral arm movements, bilateral arm movements, and sequential and alternating limb movements [79]. Movements by more distal body segments are more affected than movements by more proximal body segments.

After Mn exposure, mice commonly drag the pellet across the ledge without lifting the paw and either place the snout into the slot to retrieve the pellet with the tongue or rotate the body and "chase" the pellet with the snout when the pellet is withdrawn through the slot into the box. Those alterations could include damage to regions of the basal ganglia responsible for grasping movements [82].

With the results presented here, we confirm that bilateral DA-deficient mice have impairment in their success in retrieving food pellets. The video analysis of the reaching movements indicated that the Mn-exposed mice displayed impairment in supinating the paw to bring food to the snout. Rather than supinating, the paw was adducted across the snout so that the mouth contacted the upper surface of the paw. Food was lost because the paw is often fully pronated and moves either laterally over the pellet or the mouse slaps at the pellet from above. On the other hand, mice retained the ability to align and aim their limb to initiate a reach and to advance the limb to the food. Thus, the sensory and motor mechanisms underlying these movements must involve some motor cortical areas, which we assume intact; thus, in order to confirm that the motor alterations are due to basal ganglia damage, we utilized the beam walking test which is sensitive to impairments in the nigrostriatal pathway [83].

4.1.2. Beam Walking Test. The motor function impairments observed on the beam walking task are comparable with published findings in which C57 BL6/J mice treated with acute and subchronic dosing regimens of MPTP and were reported to display impairments in limb coordination, stride length, and motor function, at 1-2 weeks post-MPTP administration $[84,85]$. In addition, the MPTP-induced increase in duration to traverse the beam also concords with published studies in which transgenic mouse models of PD were significantly slower in traversing a narrow, raised beam than wild-type control animals [86]. Qualitative analysis showed that Mnexposed animals exhibit hind-limb weakness, delayed motor initiative (akinesia), postural instability, freezing behavior, and action tremor. Regarding these alterations, Autissier et al. [21] reported that mice subchronically exposed to Mn by intragastric gavage showed hypoactivity, this change was associated with a drop in striatal DA of 50\%; Eriksson et al. [14] found that about 5 months after the start of the Mn exposure the animals became hypoactive with an unsteady gait and subsequently an action tremor. The animals lost power in both upper and lower limbs, and the movements of the paws were very clumsy. Moreover, $\mathrm{Mn}^{3+}$ injected into the rat $\mathrm{SNc}$ decreased spontaneous motor activity, rearing behavior, and acquisition of an avoidance response [38-40].

Regarding the hyperactivity observed after 2-8 Mninhalations (Figure 5), it has been reported that in early stages of $\mathrm{Mn}$ exposure the subjects manifest psychomotor excitement, irritability, and compulsive behavior [14, 42]. Nachtman et al. [87] indicate that acute exposure to $\mathrm{Mn}$ is associated with an increase in DA neurotransmission, which is also manifested as hyperactivity. Nevertheless, longterm exposure results in a loss of DA in the brain, and the concomitant neuronal cell damage could be expressed as a decrease in motor activity. Shukla and Singhal [88] reported that acute exposure to $\mathrm{Mn}^{2+}$ causes hyperactivity accompanied by elevated brain levels of catecholamines and their metabolites. Moreover, Tomas-Camardiel et al. [57] reported that experimental rats were significantly more active than control animals in the empty open field after Mn exposure.

It has been mentioned that rats with bilateral 6-OHDA lesions have postural abnormalities at rest and a reduced capacity to maintain balance after challenges with destabilizing forces. Likewise, spontaneous movements are greatly reduced [89].

Reports of parkinsonian-like tremor have been scarce in studies of 6-OHDA-lesioned rats [90, 91]; however, Schallert et al. [92] have observed occasional resting tremor in the wrist and the paw of rats with severe DA depletion (either bilateral or unilateral). This tremor can be seen only when the forelimb is positioned off the floor in a nonweightbearing posture [92]. As it has been reported, rats with bilateral 6-OHDA lesions show all of the essential elements of parkinsonian motor syndromes. However, animals lesioned bilaterally with 6-OHDA is not a common model, as they 


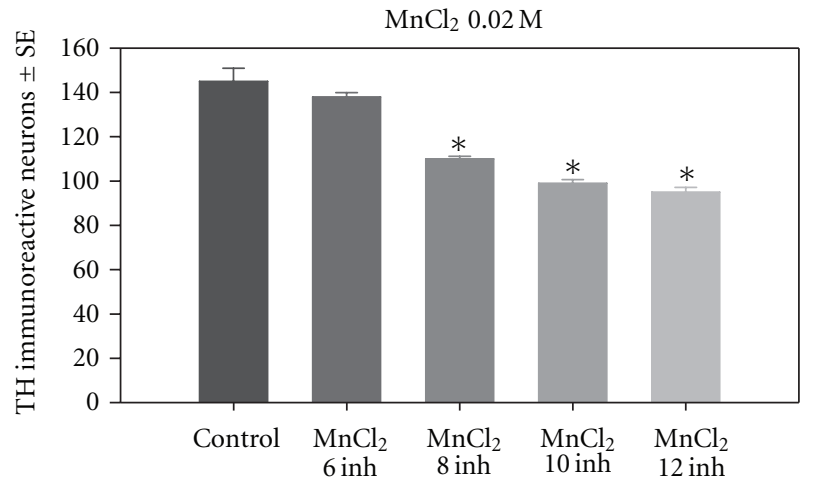

(a)

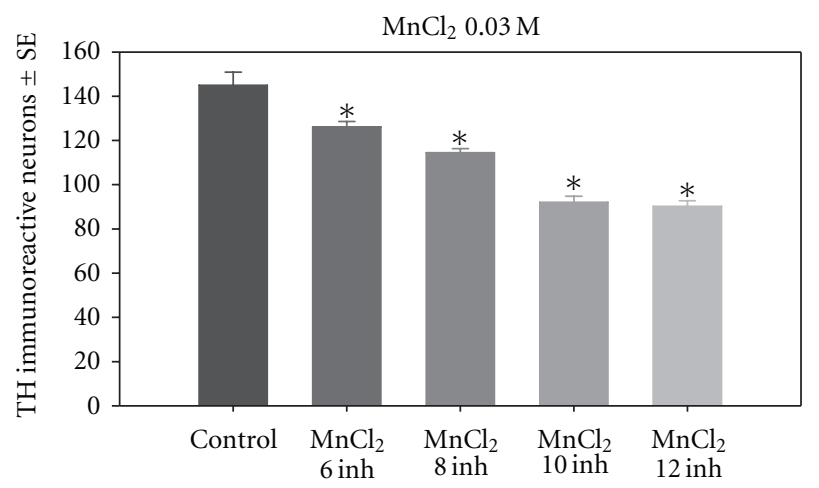

(c)

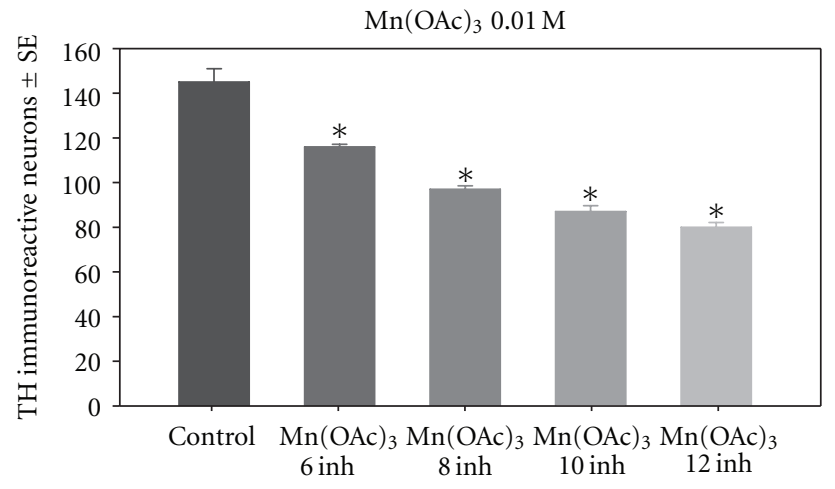

(b)

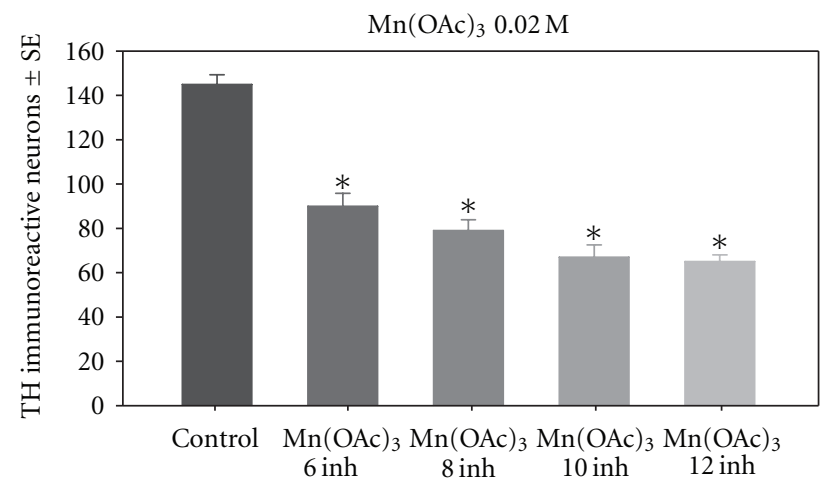

(d)

Figure 6: Pilot study. Number of $\mathrm{SNc} \mathrm{TH}^{+}$-immunostained neurons from control and exposed mice after different times of $0.02 \mathrm{M} \mathrm{MnCl}_{2}$ (a) and $0.03 \mathrm{M} \mathrm{MnCl}_{2}$ (c) inhalations and after different times of $0.01 \mathrm{M} \mathrm{Mn}(\mathrm{OAc})_{3}$ (b) and $0.02 \mathrm{M} \mathrm{Mn}(\mathrm{OAc})_{3}$ (d) inhalations. The data are presented as the mean \pm standard error $(\mathrm{SE})\left({ }^{*} P<.05\right.$ one-way ANOVA).

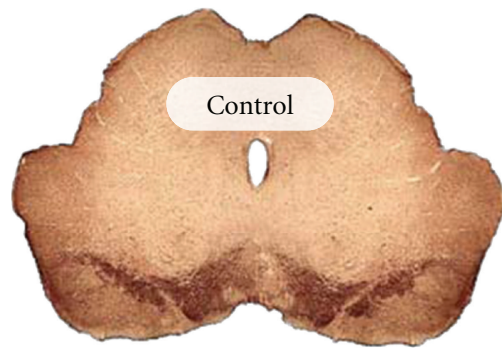

(a)

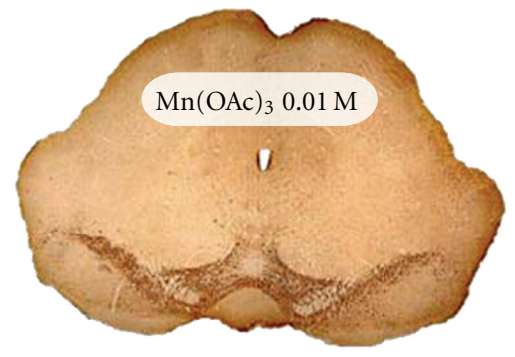

(d)

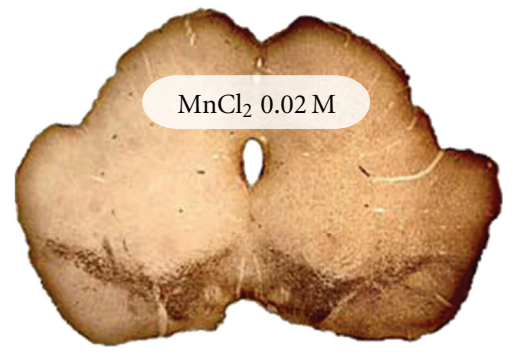

(b)

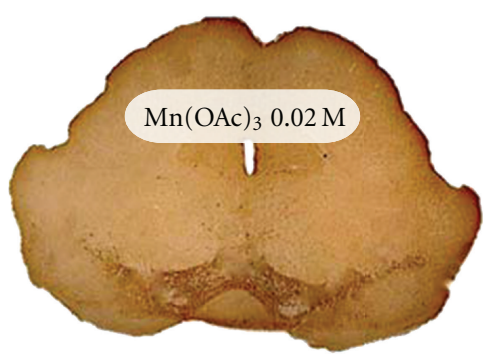

(e)

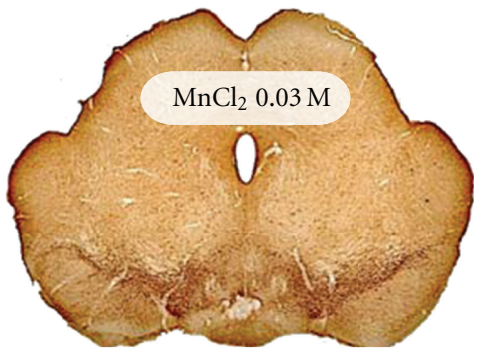

(c)

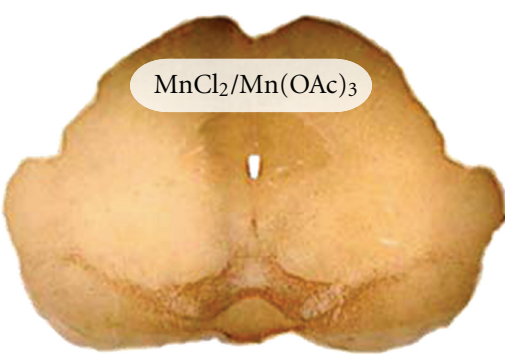

(f)

FIGURE 7: Pilot study. Representative coronal TH-immunostained sections through the SN and VTA of control and exposed mice to different Mn concentrations and compounds $(4 \mathrm{x})$. 


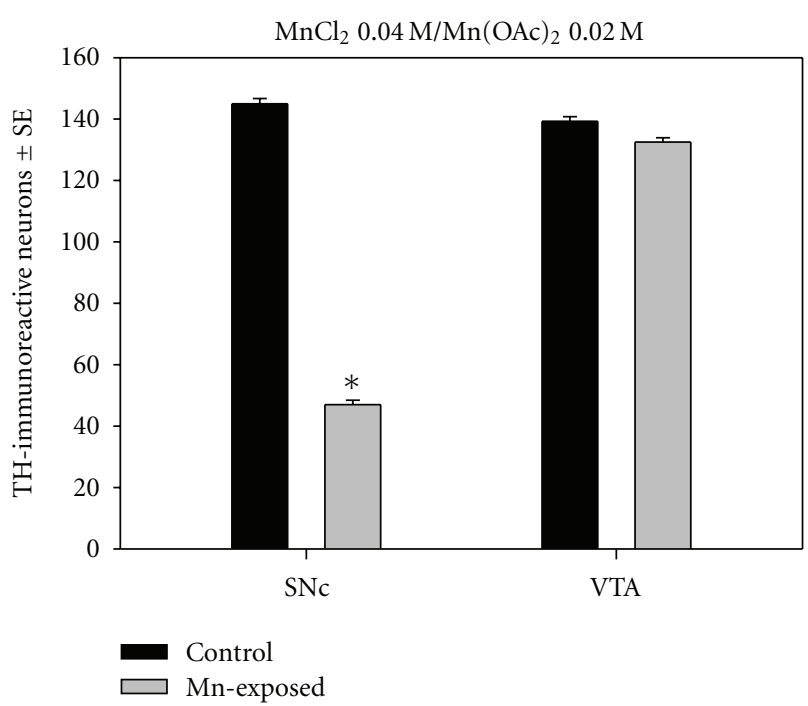

Figure 8: TH-immunoreactive cell counts from the Substantia Nigra compacta (SNc) and Ventral Tegmental Area (VTA). The data are presented as the mean $\pm \mathrm{SE}$. A statistically significant decrease in TH-immunoreactive cells was detected in the SNc $\left({ }^{*} P<.05\right.$ ANOVA test) of Mn-exposed mice compared to controls with no difference in the VTA.

require intensive nursing care [93]. So, rats with unilateral 6-OHDA lesion of the nigrostriatal dopamine pathway are the most widely used animal model of PD. However, this model does not mimic all the clinical and pathological features characteristic of PD. Furthermore, the acute nature of the experimental model differs from the progressive degeneration of the dopaminergic nigral neurons in PD.

4.1.3. TH-Immunocytochemistry. Contrary to previous reports $[12,14,18,23,42-44,57,58]$, we found an important loss of TH-positive neurons as shown in Figures 8 and 9, exhibiting a pattern very similar to that observed in $\mathrm{PD}$ patients; according to our findings, some authors have been reported neurochemical changes in human and animal Mn intoxication including the reduction in DA levels and $\mathrm{TH}^{+}$ immunoreactivity in the caudate nucleus, putamen, and SN $[7,8,21,27,54-56]$. In this way, it has been hypothesized that $\mathrm{Mn}$ interacts with catechols specific to dopaminergic neurons so as to rapidly deplete them and render such cells no longer viable $[34,66]$.

The controversy found here about the loss of TH cell count, decreased DA striatal concentrations, and the behavioral alterations, may be due to the fact that we included the mixture of $\mathrm{MnCl}_{2} / \mathrm{Mn}(\mathrm{OAc})_{3}$. According to some authors, the pro-oxidant activity of $\mathrm{Mn}^{2+}$ is dependent on trace amounts of $\mathrm{Mn}^{3+}$, which may facilitate a small portion of $\mathrm{Mn}^{2+}$ to oxidize to $\mathrm{Mn}^{3+}$. This synergistic relationship between $\mathrm{Mn}^{2+}$ and $\mathrm{Mn}^{3+}$ results in continuous redox cycling [69]. It seems that $\mathrm{Mn}^{2+}$ fails to induce oxidative effects; however, transition of $\mathrm{Mn}^{2+}$ to the trivalent state leads to an increased oxidant capacity of the metal which may result in the production of reactive oxygen species, lipid peroxidation, and cell membrane damage [59], and may in turn attack catecholamine neurotransmitters $[40,66]$; thus, the inherent convertion of $\mathrm{Mn}^{2+}$ to $\mathrm{Mn}^{3+}$ and the presence of more $\mathrm{Mn}^{3+}$ could induce more reactive oxygen species and mitochondrial disfunction $[94,95]$ manifested as the evident DA cell loss and the motor disturbances found here.

Several explanations have been proposed to elucidate the vulnerability of dopamine to $\mathrm{Mn}$, such as the impairment of cellular antioxidant defenses by the accumulation of the metal, and the disruption of mitochondrial oxidative energy metabolism [94]. This has led to the conclusion that excessive levels of brain $\mathrm{Mn}$ induce oxidative stress leading to neurodegeneration [69].

It has been mentioned that the brain is an important target of attack for transition metal ions, such as Mn, due to its great catecholamine concentration and the high speed of oxidative metabolism catalyzed by these metals [96]. DA is oxidized to aminochrome by reducing $\mathrm{Mn}^{3+}$ to $\mathrm{Mn}^{2+}$ [60], which may react with $\mathrm{O}_{2}^{-\bullet}$ radicals to generate hydrogen peroxide and more $\mathrm{Mn}^{3+}$ [66].

According to HaMai and Bondy [69], loss of the dopaminergic neurons in the nigrostriatal pathway of the basal ganglia, which are inhibitory, leads to heightened activity of neurons in the GP. Since GP efferences are also inhibitory, the sum of increased suppression of motor functions produces the symptoms characteristic of Mn-related parkinsonism. More specifically, rigidity and bradykinesia arise from the degeneration of neurons in the SNc, which project to the striatum. The Mn-induced alterations are focal to both pre- and postsynaptic terminals of the dopaminergic nigrostriatal pathway [52]. The subcellular localization of Mn occurs in the mitochondria, specifically inhibiting complex I, since Mn has a high affinity for the inner mitochondrial membrane $[32,54,68,95]$. Salient features of the brain regions susceptible to Mn-provoked injury include their intense oxidative metabolism, major DA content, and high content of nonheme iron [32, 59, 69]. This raises the possibility that the mechanisms of Mn neurotoxicity relate to its potential for oxidative injury and promotion of DA auto-oxidation $[36,66]$. The mechanisms by which the common neurotoxins kill dopaminergic neurons also involve mitochondrial dysfunction and oxidative damage. 6-OHDA is taken up by DAT, and it then generates free radicals [97]. MPTP is converted by monoamine oxidase B to 1-methyl4-phenylpyridinium (MPP+). MPP+ is taken up by DAT and can then be accumulated by mitochondria, leading to complex I inhibition and the generation of free radicals [98]. In this way, Hirata et al. [99] suggest that the mechanisms by which Mn produces dysfunction of the nervous system are similar to those of MPTP.

It is also worth noting that, in this study, although Mninhalation caused significant damage to dopaminergic neurons in the SNc, the dopaminergic neurons in VTA did not appear to be affected. It is not clear whether this suggests any selectivity in Mn-induced toxicity between dopaminergic neurons in the SNc and those in the VTA; however, it has been mentioned that $\mathrm{Mn}$ enters the neurons possibly via DAT [29-31]; DAT has been shown to be involved in the selective neurotoxicity of MPTP [98], 6-OHDA [97], and that of Thiruchelvam et al. [27], where SNc is more 


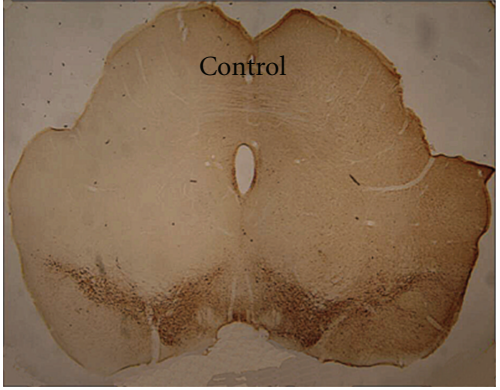

(a)

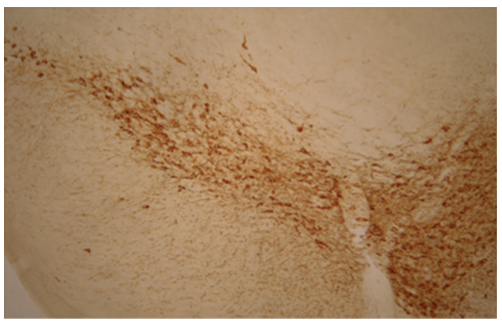

(c)

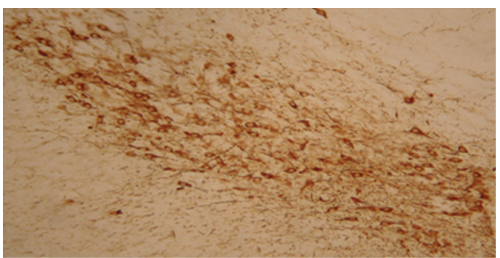

(e)

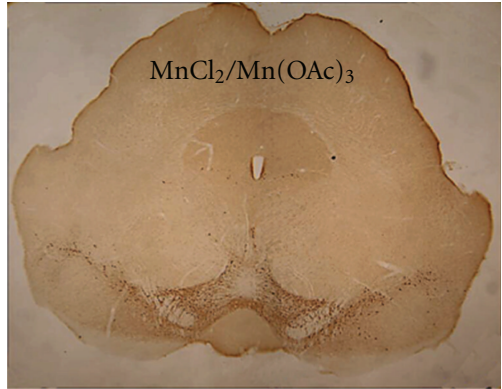

(b)

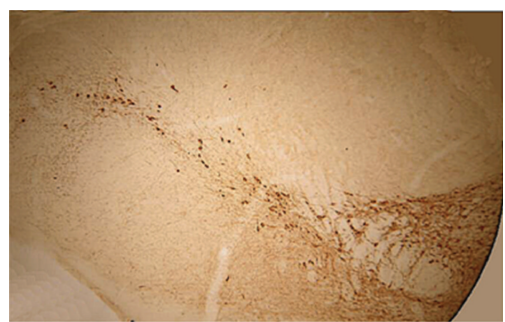

(d)

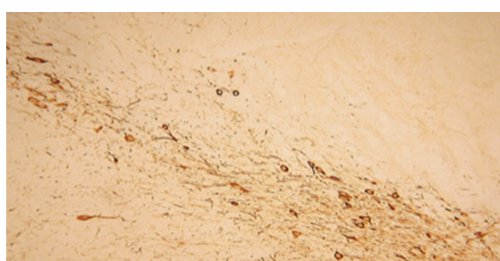

(f)

FIGURE 9: Representative TH-immunostained from coronal section containing the SN and VTA of control and Mn-exposed mice. Note the relative sparing in the ventral tegmental area and profound cell loss at all levels of SNc in the Mn-exposed group (upper panel 4x, middle panel 10,000x, and lower panel 40,000x).

susceptible than VTA. It seems that dopaminergic cells of the SNc and the VTA display differences in their topography, biochemistry, and susceptibility to pathological processes [100], VTA express lower levels of DAT than the middle and medial SNc $[98,101]$; thus, it is possible that Mn reaches SNc dopaminergic cells via the large amounts of DAT found on those neurons; however, additional studies are needed.

Currently available animal models of PD have contributed greatly to our understanding of both the pathophysiology and potential neuroprotective therapeutics for $\mathrm{PD}$, but as yet we do not have the optimal model. At present, MPTP neurotoxicity is the best available animal model from several standpoints, and it has been extremely valuable in testing neuroprotective and neurorestorative strategies. Nevertheless, the disadvantages of the MPTP model are: acute damage of the dopaminergic system and nonprogressive and rare generation of inclusion bodies [102]. Both, 6-OHDA and MPTP models differ significantly from the slowly progressive pathology of human PD [4]. In addition, genetic mouse models of PD have previously been observed to repeat some aspects of the disease in the absence of substantial neuronal loss in the affected brain subregions [103]. Transgenic mice overexpressing wild-type and FPD-linked mutant human alfa-synuclein exhibit motor deficits in the absence of loss of DA neurons $[4,104]$.

The significant decrease $(67.58 \%)$ in the number of $\mathrm{SNc} \mathrm{TH}$-immunopositive neurons after $\mathrm{MnCl}_{2} / \mathrm{Mn}(\mathrm{OAc})_{3}$ inhalation and the evident reduction of striatal dopamine concentrations reported here demonstrates a glaring reduction of this chatecolamine content (71\%). Hence, we assume that the alterations are due to dopaminergic loss since L-DOPA-treated mice almost completely improved their motor performance.

It has been reported that Mn effects involve the GP [43, 44, 105]; however, with these results we can assure that the $\mathrm{MnCl}_{2} / \mathrm{Mn}(\mathrm{OAc})_{3}$ mixture also jeopardizes the nigrostriatal pathway. In this study, we have demonstrated that L-DOPA treatment significantly improves the motor alterations found after Mn exposure, suggesting that these motor disturbances are of dopaminergic origin. Moreover, Mn mixture inhalation was extensive enough to induce substantial and stable deficits in spontaneous sensorimotor behaviors including tremor, posture instability, slowed movement, and rigidity; and in contrast to the complete nigrostriatal bundle lesion produced by other PD models such as 6-OHDA, which is the most commonly used model in functional experimental 
studies, the Mn mixture inhalation leaves a considerable portion of the nigrostriatal projection intact. As in early stages of PD, the presence of an intact, functioning subportion of the nigrostriatal system could allow L-DOPA treatment to be efficient.

In summary, the results from this study suggest that the motor alterations induced by the inhalation of the combination of $\mathrm{MnCl}_{2} / \mathrm{Mn}(\mathrm{OAc})_{3}$ are related to nigrostriatal dopaminergic function, providing new light on the understanding of Mn neurotoxicity as a suitable PD experimental model.

In conclusion the data described in the present study provides further evidence that functional deficits following Mn exposure in mice can be quantified and are related to nigrostriatal DA function. The motor and immunocytochemical discrepancies reported here are probably due to the combination of $\mathrm{MnCl}_{2} / \mathrm{Mn}(\mathrm{OAc})_{3}$, since it has been reported that $\mathrm{Mn}^{3+}$ is more potent in producing oxidative stress and cell damage and $\mathrm{Mn}^{2+}$ needs the presence of $\mathrm{Mn}^{3+}$ to reach oxidation and that there is a synergy between the two Mn states, and so far, there is no research that has included this mixture. Therefore, we consider that the inhalation of $\mathrm{MnCl}_{2} / \mathrm{Mn}(\mathrm{OAc})_{3}$ mixture could be an appropriate $\mathrm{PD}$ model.

\section{Acknowledgments}

The authors thank Dr. Liliana Saldivar Osorio (Facultad de Química UNAM) for the measurement of Mn concentration and Jesus Espinosa Villanueva and Patricia Aley Medina for their excellent photographical and technical assistance. This paper is supported by PAPIIT-DGAPA-UNAM IN-215708 and PAPCA-Iztacala UNAM 2009-2010.

\section{References}

[1] A. E. Lang and A. M. Lozano, "Parkinson's disease: first of two parts," New England Journal of Medicine, vol. 339, no. 16, pp. 1130-1143, 1998.

[2] S. B. Dunnett and A. Björklund, "Prospects for new restorative and neuroprotective treatments in Parkinson's disease," Nature, vol. 399, supplement 6738, pp. A32-A39, 1999.

[3] C. W. Olanow and W. G. Tatton, "Etiology and pathogenesis of Parkinson's disease," Annual Review of Neuroscience, vol. 22, pp. 123-144, 1999.

[4] R. Betarbet, T. B. Sherer, and J. T. Greenamyre, "Animal models of Parkinson's disease," BioEssays, vol. 24, no. 4, pp. 308-318, 2002.

[5] M. E. Emborg, "Evaluation of animal models of Parkinson's disease for neuroprotective strategies," Journal of Neuroscience Methods, vol. 139, no. 2, pp. 121-143, 2004.

[6] D. G. Cook, S. Fahn, and K. A. Brait, "Chronic manganese intoxication," Archives of Neurology, vol. 30, no. 1, pp. 59-64, 1974.

[7] D. B. Calne, N. S. Chu, C. C. Huang, C. S. Lu, and W. Olanow, "Manganism and idiopathic parkinsonism: similarities and differences," Neurology, vol. 44, no. 9, pp. 1583-1586, 1994.

[8] P. K. Pal, A. Samii, and D. B. Calne, "Manganese neurotoxicity: a review of clinical features, imaging and pathology," NeuroToxicology, vol. 20, no. 2-3, pp. 227-238, 1999.
[9] J. Couper, "On the effects of black oxide of manganese when inhaled in the lungs," British Annals of Medicine, vol. 1, pp. 41-42, 1837.

[10] C. C. Huang, "Parkinsonism induced by chronic manganese intoxication-an experience in Taiwan," Chang Gung Medical Journal, vol. 30, no. 5, pp. 385-395, 2007.

[11] R. M. A. De Bie, R. M. Gladstone, A. P. Strafella, J. H. Ko, and A. E. Lang, "Manganese-induced parkinsonism associated with methcathinone (Ephedrone) abuse," Archives of Neurology, vol. 64, no. 6, pp. 886-889, 2007.

[12] M. Yamada, S. Ohno, and I. Okayasu, "Chronic manganese poisoning: a neuropathological study with determination of manganese distribution in the brain," Acta Neuropathologica, vol. 70, no. 3-4, pp. 273-278, 1986.

[13] B. A. Racette, L. McGee-Minnich, S. M. Moerlein, J. W. Mink, T. O. Videen, and J. S. Perlmutter, "Welding-related parkinsonism: clinical-features, treatment, and pathophysiology," Neurology, vol. 56, no. 1, pp. 8-13, 2001.

[14] H. Eriksson, K. Mägiste, L. O. Plantin et al., "Effects of manganese oxide on monkeys as revealed by a combined neurochemical, histological and neurophysiological evaluation," Archives of Toxicology, vol. 61, no. 1, pp. 46-52, 1987.

[15] H. Eriksson, J. Tedroff, K. A. Thuomas et al., "Manganese induced brain lesions in Macaca fascicularis as revealed by positron emission tomography and magnetic resonance imaging," Archives of Toxicology, vol. 66, no. 6, pp. 403-407, 1992.

[16] T. R. Guilarte, N. C. Burton, J. L. McGlothan et al., "Impairment of nigrostriatal dopamine neurotransmission by manganese is mediated by pre-synaptic mechanism(s): implications to manganese-induced parkinsonism," Journal of Neurochemistry, vol. 107, no. 5, pp. 1236-1247, 2008.

[17] T. R. Guilarte, M. K. Chen, J. L. McGlothan et al., "Nigrostriatal dopamine system dysfunction and subtle motor deficits in manganese-exposed non-human primates," Experimental Neurology, vol. 202, no. 2, pp. 381-390, 2006.

[18] M. F. Struve, B. E. McManus, B. A. Wong, and D. C. Dorman, "Basal ganglia neurotransmitter concentrations in rhesus monkeys following subchronic manganese sulfate inhalation," American Journal of Industrial Medicine, vol. 50, no. 10, pp. 772-778, 2007.

[19] E. Bonilla, "L-tyrosine hydroxylase activity in the rat brain after chronic oral administration of manganese chloride," Neurobehavioral Toxicology and Teratology, vol. 2, no. 1, pp. 37-41, 1980.

[20] S. V. Chandra and G. S. Shukla, "Concentrations of striatal catecholamines in rats given manganese chloride through drinking water," Journal of Neurochemistry, vol. 36, no. 2, pp. 683-687, 1981.

[21] N. Autissier, L. Rochette, and P. Dumas, "Dopamine and norepinephrine turnover in various regions of the rat brain after chronic manganese chloride administration," Toxicology, vol. 24, no. 2, pp. 175-182, 1982.

[22] G. Gianutsos and M. T. Murray, "Alterations in brain dopamine and GABA following inorganic or organic manganese administration," NeuroToxicology, vol. 3, no. 3, pp. 75-81, 1982.

[23] X. Liu, K. A. Sullivan, J. E. Madl, M. Legare, and R. B. Tjalkens, "Manganese-induced neurotoxicity: the role of astroglial-derived nitric oxide in striatal interneuron degeneration," Toxicological Sciences, vol. 91, no. 2, pp. 521$531,2006$.

[24] C. W. Olanow, P. F. Good, H. Shinotoh et al., "Manganese intoxication in the rhesus monkey: a clinical, imaging, 
pathologic, and biochemical study," Neurology, vol. 46, no. 2, pp. 492-498, 1996.

[25] L. Normandin, M. Panisset, and J. Zayed, "Manganese neurotoxicity: behavioral, pathological, and biochemical effects following various routes of exposure," Reviews on Environmental Health, vol. 17, no. 3, pp. 189-217, 2002.

[26] D. C. Dorman, M. F. Struve, H. J. Clewell, and M. E. Andersen, "Application of pharmacokinetic data to the risk assessment of inhaled manganese," NeuroToxicology, vol. 27, no. 5, pp. 752-764, 2006.

[27] M. Thiruchelvam, E. K. Richfield, R. B. Baggs, A. W. Tank, and D. A. Cory-Slechta, "The nigrostriatal dopaminergic system as a preferential target of repeated exposures to combined paraquat and maneb: implications for Parkinson's disease," Journal of Neuroscience, vol. 20, no. 24, pp. 92079214, 2000.

[28] M. K. Chen, J. S. Lee, J. L. McGlothan et al., "Acute manganese administration alters dopamine transporter levels in the non-human primate striatum," NeuroToxicology, vol. 27, no. 2, pp. 229-236, 2006.

[29] R. T. Ingersoll, E. B. Montgomery, and H. V. Aposhian, "Central nervous system toxicity of manganese II: cocaine or reserpine inhibit manganese concentration in the rat brain," NeuroToxicology, vol. 20, no. 2-3, pp. 467-476, 1999.

[30] K. M. Erikson, C. E. John, S. R. Jones, and M. Aschner, "Manganese accumulation in striatum of mice exposed to toxic doses is dependent upon a functional dopamine transporter," Environmental Toxicology and Pharmacology, vol. 20, no. 3, pp. 390-394, 2005.

[31] J. G. Anderson, P. T. Cooney, and K. M. Erikson, "Inhibition of DAT function attenuates manganese accumulation in the globus pallidus," Environmental Toxicology and Pharmacology, vol. 23, no. 2, pp. 179-184, 2007.

[32] C. E. Gavin, K. K. Gunter, and T. E. Gunter, " $\mathrm{Mn}^{2+}$ sequestration by mitochondria and inhibition of oxidative phosphorylation," Toxicology and Applied Pharmacology, vol. 115, no. 1, pp. 1-5, 1992.

[33] E. F. Soliman, W. Slikker, and S. F. Ali, "Manganese-induced oxidative stress as measured by a fluorescent probe: an in vitro study," Neuroscience Research Communications, vol. 17, no. 3, pp. 185-193, 1995.

[34] J. Donaldson, D. McGregor, and F. LaBella, "Manganese neurotoxicity: a model for free radical mediated neurodegeneration," Canadian Journal of Physiology and Pharmacology, vol. 60, no. 11, pp. 1398-1405, 1982.

[35] T. M. Florence and J. L. Stauber, "Manganese catalysis of dopamine oxidation," Science of the Total Environment, vol. 78, pp. 233-240, 1989.

[36] W. N. Sloot, J. Korf, J. F. Koster, L. E. A. De Wit, and J. B. P. Gramsbergen, "Manganese-induced hydroxyl radical formation in rat striatum is not attenuated by dopamine depletion or iron chelation in vivo," Experimental Neurology, vol. 138, no. 2, pp. 236-245, 1996.

[37] B. Xu, Z. F. Xu, and Y. Deng, "Manganese exposure alters the expression of N-methyl-D-aspartate receptor subunit mRNAs and proteins in rat striatum," Journal of Biochemical and Molecular Toxicology, vol. 24, no. 1, pp. 1-9, 2010.

[38] E. P. Brouillet, L. Shinobu, U. McGarvey, F. Hochberg, and M. F. Beal, "Manganese injection into the rat striatum produces excitotoxic lesions by impairing energy metabolism," Experimental Neurology, vol. 120, no. 1, pp. 89-94, 1993.
[39] A. J. Daniels and J. Abarca, "Effect of intranigral Mn on striatal and nigral synthesis and levels of dopamine and cofactor," Neurotoxicology and Teratology, vol. 13, no. 5, pp. 483-487, 1991.

[40] G. Díaz-Véliz, S. Mora, P. Gómez et al., "Behavioral effects of manganese injected in the rat substantia nigra are potentiated by dicumarol, a DT-diaphorase inhibitor," Pharmacology Biochemistry and Behavior, vol. 77, no. 2, pp. 245-251, 2004.

[41] A. B. Santamaria and S. I. Sulsky, "Risk assessment of an essential element: manganese," Journal of Toxicology and Environmental Health. Part A, vol. 73, no. 2-3, pp. 128-155, 2010.

[42] P. Calabresi, M. Ammassari-Teule, P. Gubellini et al., "A synaptic mechanism underlying the behavioral abnormalities induced by manganese intoxication," Neurobiology of Disease, vol. 8, no. 3, pp. 419-432, 2001.

[43] C. W. Olanow, "Manganese-induced parkinsonism and parkinson's disease," Annals of the New York Academy of Sciences, vol. 1012, pp. 209-223, 2004.

[44] D. P. Perl and C. W. Olanow, "The neuropathology of manganese-induced parkinsonism," Journal of Neuropathology and Experimental Neurology, vol. 66, no. 8, pp. 675-682, 2007.

[45] R. G. Lucchini, C. J. Martin, and B. C. Doney, "From manganism to manganese-induced parkinsonism: a conceptual model based on the evolution of exposure," NeuroMolecular Medicine, vol. 11, no. 4, pp. 311-321, 2009.

[46] T. R. Guilarte, "Manganese and Parkinson's disease: a critical review and new findings," Environmental Health Perspectives, vol. 118, no. 8, pp. 1071-1080, 2010.

[47] C. S. Lu, C. C. Huang, N. S. Chu, and D. B. Calne, "Levodopa failure in chronic manganism," Neurology, vol. 44, no. 9, pp. 1600-1602, 1994.

[48] M. G. Cersosimo and W. C. Koller, "The diagnosis of manganese-induced parkinsonism," NeuroToxicology, vol. 27, no. 3, pp. 340-346, 2006.

[49] M. Aschner, K. M. Erikson, E. H. Hernández, and R. Tjalkens, "Manganese and its role in Parkinson's disease: from transport to neuropathology," NeuroMolecular Medicine, vol. 11, no. 4, pp. 252-266, 2009.

[50] M. Aschner, T. R. Guilarte, J. S. Schneider, and W. Zheng, "Manganese: recent advances in understanding its transport and neurotoxicity," Toxicology and Applied Pharmacology, vol. 221, no. 2, pp. 131-147, 2007.

[51] R. Gwiazda, R. Lucchini, and D. Smith, "Adequacy and consistency of animal studies to evaluate the neurotoxicity of chronic low-level manganese exposure in humans," Journal of Toxicology and Environmental Health. Part A, vol. 70, no. 7, pp. 594-605, 2007.

[52] W. N. Sloot, A. J. Van der Sluijs-Gelling, and J. B. P. Gramsbergen, "Selective lesions by manganese and extensive damage by iron after injection into rat striatum or hippocampus," Journal of Neurochemistry, vol. 62, no. 1, pp. 205-216, 1994.

[53] H. S. Chun, H. Lee, and J. H. Son, "Manganese induces endoplasmic reticulum (ER) stress and activates multiple caspases in nigral dopaminergic neuronal cells, SN4741," Neuroscience Letters, vol. 316, no. 1, pp. 5-8, 2001.

[54] J. Zhang, V. A. Fitsanakis, G. Gu et al., "Manganese ethylenebis-dithiocarbamate and selective dopaminergic neurodegeneration in rat: a link through mitochondrial dysfunction," Journal of Neurochemistry, vol. 84, no. 2, pp. 336-346, 2003.

[55] S. C. Sistrunk, M. K. Ross, and N. M. Filipov, "Direct effects of manganese compounds on dopamine and its metabolite 
Dopac: an in vitro study," Environmental Toxicology and Pharmacology, vol. 23, no. 3, pp. 286-296, 2007.

[56] K. Sriram, G. X. Lin, A. M. Jefferson et al., "Dopaminergic neurotoxicity following pulmonary exposure to manganesecontaining welding fumes," Archives of Toxicology, vol. 84, no. 7, pp. 521-540, 2010.

[57] M. Tomás-Camardiel, A. J. Herrera, J. L. Venero, M. Cruz Sánchez-Hidalgo, J. Cano, and A. Machado, "Differential regulation of glutamic acid decarboxylase mRNA and tyrosine hydroxylase mRNA expression in the aged manganesetreated rats," Molecular Brain Research, vol. 103, no. 1-2, pp. 116-129, 2002.

[58] R. H. Gwiazda, D. Lee, J. Sheridan, and D. R. Smith, "Low cumulative manganese exposure affects striatal GABA but not dopamine," NeuroToxicology, vol. 95, no. 1, pp. 1-8, 2002.

[59] M. S. Desole, G. Esposito, R. Migheli et al., "Allopurinol protects against manganese-induced oxidative stress in the striatum and in the brainstem of the rat," Neuroscience Letters, vol. 192, no. 2, pp. 73-76, 1995.

[60] J. Segura-Aguilar and C. Lind, "On the mechanism of the Mn-induced neurotoxicity of dopamine: prevention of quinone-derived oxygen toxicity by DT diaphorase and superoxide dismutase," Chemico-Biological Interactions, vol. 72, no. 3, pp. 309-324, 1989.

[61] R. A. Yokel, "Manganese flux across the blood-brain barrier," NeuroMolecular Medicine, vol. 11, no. 4, pp. 297-310, 2009.

[62] A. Takeda, "Manganese action in brain function," Brain Research Reviews, vol. 41, no. 1, pp. 79-87, 2003.

[63] C. Au, A. Benedetto, and M. Aschner, "Manganese transport in eukaryotes: the role of DMT1," NeuroToxicology, vol. 29, no. 4, pp. 569-576, 2008.

[64] J. R. Burdo, J. Martin, S. L. Menzies et al., "Cellular distribution of iron in the brain of the Belgrade rat," Neuroscience, vol. 93, no. 3, pp. 1189-1196, 1999.

[65] A. S. Hazell, "Astrocytes and manganese neurotoxicity," Neurochemistry International, vol. 41, no. 4, pp. 271-277, 2002.

[66] F. S. Archibald and C. Tyree, "Manganese poisoning and the attack of trivalent manganese upon catecholamines," Archives of Biochemistry and Biophysics, vol. 256, no. 2, pp. 638-650, 1987.

[67] S. F. Ali, H. M. Duhart, G. D. Newport, G. W. Lipe, and W. Slikker, "Manganese-induced reactive oxygen species: comparison between $\mathrm{Mn}^{+2}$ and $\mathrm{Mn}^{+3}$," Neurodegeneration, vol. 4, no. 3, pp. 329-334, 1995.

[68] J. Y. Chen, G. C. Tsao, Q. Zhao, and W. Zheng, "Differential cytotoxicity of $\mathrm{Mn}(\mathrm{II})$ and $\mathrm{Mn}(\mathrm{III})$ : special reference to mitochondrial $[\mathrm{Fe}-\mathrm{S}]$ containing enzymes," Toxicology and Applied Pharmacology, vol. 175, no. 2, pp. 160-168, 2001.

[69] D. HaMai and S. C. Bondy, "Oxidative basis of manganese neurotoxicity," Annals of the New York Academy of Sciences, vol. 1012, pp. 129-141, 2004.

[70] I. Q. Whishaw, S. M. Pellis, B. P. Gorny, and V. C. Pellis, "The impairments in reaching and the movements of compensation in rats with motor cortex lesions: an endpoint, videorecording, and movement notation analysis," Behavioural Brain Research, vol. 42, no. 1, pp. 77-91, 1991.

[71] T. D. Farr and I. Q. Whishaw, "Quantitative and qualitative impairments in skilled reaching in the mouse (Mus musculus) after a focal motor cortex stroke," Stroke, vol. 33, no. 7, pp. 1869-1875, 2002.

[72] T. A. Perry, E. M Torres, C. Czech, K. Beyreuther, S. Richards, and S. B. Dunnett, "Cognitive and motor function in transgenic mice carrying excess copies of the 695 and 751 amino acid isoforms of the amyloid precursor protein gene," Alzheimer's Research, vol. 1, pp. 5-14, 1995.

[73] M. R. Avila-Costa, E. Montiel Flores, L. Colin-Barenque et al., "Nigrostriatal modifications after vanadium inhalation: an immunocytochemical and cytological approach," Neurochemical Research, vol. 29, no. 7, pp. 1365-1369, 2004.

[74] D. Martinez-Fong, M. G. Rosales, J. L. Gongora-Alfaro, S. Hernandez, and J. Aceves, "NMDA receptor mediates dopamine release in the striatum of unanaesthetized rats as measured by brain microdialysis," Brain Research, vol. 595, no. 2, pp. 309-315, 1992.

[75] M. M. Bradford, "A rapid and sensitive method for the quantitation of microgram quantities of protein utilizing the principle of protein dye binding," Analytical Biochemistry, vol. 72, no. 1-2, pp. 248-254, 1976.

[76] T. I. Fortoul, R. C. Salgado, S. G. Moncada et al., "Ultrastructural findings in the murine Nonciliated Bronchiolar Cells (NCBC) after subacute inhalation of lead acetate," Acta Veterinaria Brno, vol. 68, no. 1, pp. 51-55, 1999.

[77] J. Biernaskie, G. Chernenko, and D. Corbett, "Efficacy of rehabilitative experience declines with time after focal ischemic brain injury," Journal of Neuroscience, vol. 24, no. 5, pp. 1245-1254, 2004.

[78] G. A. S. Metz, T. Farr, M. Ballermann, and I. Q. Whishaw, "Chronic levodopa therapy does not improve skilled reach accuracy or reach range on a pasta matrix reaching task in 6-OHDA dopamine-depleted (hemi-Parkinson analogue) rats," European Journal of Neuroscience, vol. 14, no. 1, pp. 2737, 2001.

[79] I. Q. Whishaw, O. Suchowersky, L. Davis, J. Sarna, G. A. Metz, and S. M. Pellis, "Impairment of pronation, supination, and body co-ordination in reach-to-grasp tasks in human Parkinson's disease (PD) reveals homology to deficits in animal models," Behavioural Brain Research, vol. 133, no. 2, pp. 165-176, 2002.

[80] U. Castiello, K. Bennett, C. Bonfiglioli, S. Lim, and R. F. Peppard, "The reach-to-grasp movement in Parkinson's disease: response to a simultaneous perturbation of object position and object size," Experimental Brain Research, vol. 125, no. 4, pp. 453-462, 1999.

[81] G. M. Jackson, S. R. Jackson, and J. V. Hindle, "The control of bimanual reach-to-grasp movements in hemiparkinsonian patients," Experimental Brain Research, vol. 132, no. 3, pp. 390-398, 2000.

[82] C. L. MacLellan, S. Gyawali, and F. Colbourne, "Skilled reaching impairments follow intrastriatal hemorrhagic stroke in rats," Behavioural Brain Research, vol. 175, no. 1, pp. 82-89, 2006.

[83] F. Garcia-Hernandez, M. T. Pacheco-Cano, and R. DruckerColin, "Reduction of motor impairment by adrenal medulla transplant in aged rats," Physiology and Behavior, vol. 54, no. 3, pp. 589-598, 1993.

[84] N. Ogawa, Y. Hirose, and S. Ohara, "A simple quantitative bradykinesia test in MPTP-treated mice," Research Communications in Chemical Pathology and Pharmacology, vol. 50, no. 3, pp. 435-441, 1985.

[85] P. O. Fernagut, E. Diguet, B. Labattu, and F. Tison, "A simple method to measure stride length as an index of nigrostriatal dysfunction in mice," Journal of Neuroscience Methods, vol. 113, no. 2, pp. 123-130, 2002.

[86] D. Y. Hwang, S. M. Fleming, P. Ardayfio et al., "3,4Dihydroxyphenylalanine reverses the motor deficits in Pitx3-deficient Aphakia mice: behavioral characterization of 
a novel genetic model of Parkinson's disease," Journal of Neuroscience, vol. 25, no. 8, pp. 2132-2137, 2005.

[87] J. P. Nachtman, R. E. Tubben, and R. L. Commissaris, "Behavioral effects of chronic manganese administration in rats: locomotor activity studies," Neurobehavioral Toxicology and Teratology, vol. 8, no. 6, pp. 711-715, 1986.

[88] G. S. Shukla and R. L. Singhal, "The present status of biological effects of toxic metals in the environment: lead, cadmium, and manganese," Canadian Journal of Physiology and Pharmacology, vol. 62, no. 8, pp. 1015-1031, 1984.

[89] A. Rödter, C. Winkler, M. Samii, and G. Nikkhah, "Complex sensorimotor behavioral changes after terminal striatal 6OHDA lesion and transplantation of dopaminergic embryonic micrografts," Cell Transplantation, vol. 9, no. 2, pp. 197$214,2000$.

[90] M. D. Lindner, C. K. Cain, M. A. Plone et al., "Incomplete nigrostriatal dopaminergic cell loss and partial reductions in striatal dopamine produce akinesia, rigidity, tremor and cognitive deficits in middle-aged rats," Behavioural Brain Research, vol. 102, no. 1-2, pp. 1-16, 1999.

[91] M. A. Cenci, I. Q. Whishaw, and T. Schallert, "Animal models of neurological deficits: how relevant is the rat?" Nature Reviews Neuroscience, vol. 3, no. 7, pp. 574-579, 2002.

[92] T. Schallert, B. F. Petrie, and I. Q. Whishaw, "Neonatal dopamine depletion: spared and unspared sensorimotor and attentional disorders and effects of further depletion in adulthood," Psychobiology, vol. 17, no. 4, pp. 386-396, 1989.

[93] U. Ungerstedt, "Adipsia and aphagia after 6hydroxydopamine induced degeneration of the nigro-striatal dopamine system," Acta Physiologica Scandinavica, vol. 367, supplement, pp. 95-122, 1971.

[94] M. Morello, A. Canini, P. Mattioli et al., "Sub-cellular localization of manganese in the basal ganglia of normal and manganese-treated rats. An electron spectroscopy imaging and electron energy-loss spectroscopy study," NeuroToxicology, vol. 29, no. 1, pp. 60-72, 2008.

[95] T. E. Gunter, C. E. Gavin, M. Aschner, and K. K. Gunter, "Speciation of manganese in cells and mitochondria: a search for the proximal cause of manganese neurotoxicity," NeuroToxicology, vol. 27, no. 5, pp. 765-776, 2006.

[96] A. H. Stokes, T. G. Hastings, and K. E. Vrana, "Cytotoxic and genotoxic potential of dopamine," Journal of Neuroscience Research, vol. 55, no. 6, pp. 659-665, 1999.

[97] A. S. Perumal, V. B. Gopal, W. K. Tordzro, T. B. Cooper, and J. L. Cadet, "Vitamin E attenuates the toxic effects of 6hydroxydopamine on free radical scavenging systems in rat brain," Brain Research Bulletin, vol. 29, no. 5, pp. 699-701, 1992.

[98] S. N. Haber, H. Ryoo, C. Cox, and W. Lu, "Subsets of midbrain dopaminergic neurons in monkeys are distinguished by different levels of mRNA for the dopamine transporter: comparison with the mRNA for the D receptor, tyrosine hydroxylase and calbindin immunoreactivity," Journal of Comparative Neurology, vol. 362, no. 3, pp. 400-410, 1995.

[99] Y. Hirata, K. Kiuchi, and T. Nagatsu, "Manganese mimics the action of 1-methyl-4-phenylpyridinium ion, a dopaminergic neurotoxin, in rat striatal tissue slices," Neuroscience Letters, vol. 311, no. 1, pp. 53-56, 2001.

[100] G. R. Uhl, "Hypothesis: the role of dopaminergic transporters in selective vulnerability of cells in Parkinson's disease," Annals of Neurology, vol. 43, no. 5, pp. 555-560, 1998.

[101] B. J. Ciliax, G. W. Drash, J. K. Staley et al., "Immunocytochemical localization of the dopamine transporter in human brain," The Journal of Comparative Neurology, vol. 409, no. 1, pp. 38-56, 1999.

[102] A. Schober, "Classic toxin-induced animal models of Parkinsons disease: 6-OHDA and MPTP," Cell and Tissue Research, vol. 318, no. 1, pp. 215-224, 2004.

[103] M. S. Goldberg, S. M. Fleming, J. J. Palacino et al., "Parkindeficient mice exhibit nigrostriatal deficits but not loss of dopaminergic neurons," Journal of Biological Chemistry, vol. 278, no. 44, pp. 43628-43635, 2003.

[104] B. I. Giasson, J. E. Duda, S. M. Quinn, B. Zhang, J. Q. Trojanowski, and V. M. Y. Lee, "Neuronal $\alpha$-synucleinopathy with severe movement disorder in mice expressing A53T human $\alpha$-synuclein," Neuron, vol. 34, no. 4, pp. 521-533, 2002.

[105] V. W. Yong, T. L. Perry, and W. J. Godolphin, "Chronic organic manganese administration in the rat does not damage dopaminergic nigrostriatal neurons," NeuroToxicology, vol. 7 , no. 1, pp. 19-24, 1986. 


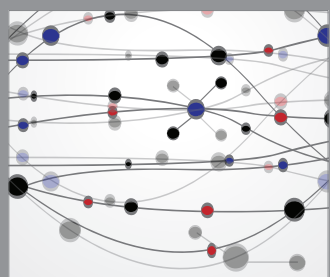

The Scientific World Journal
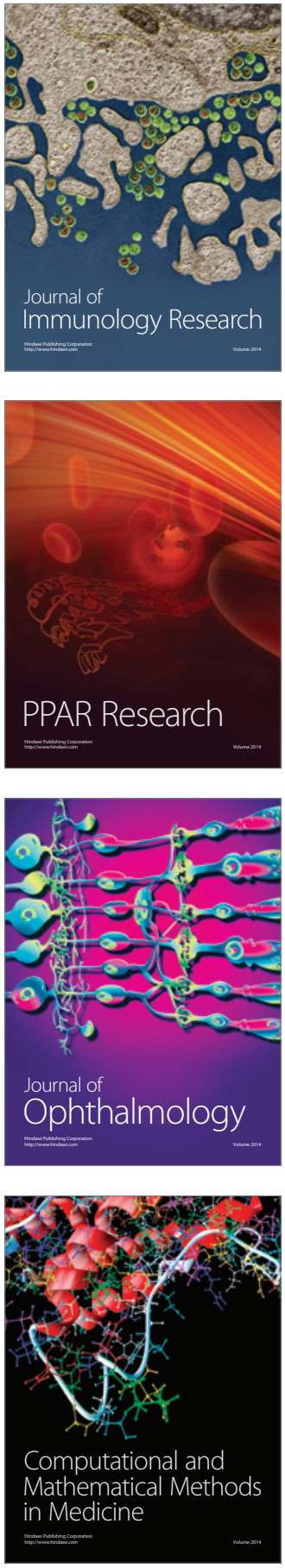

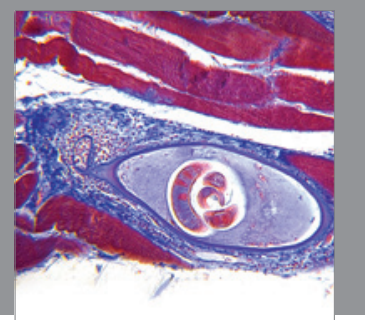

Gastroenterology

Research and Practice
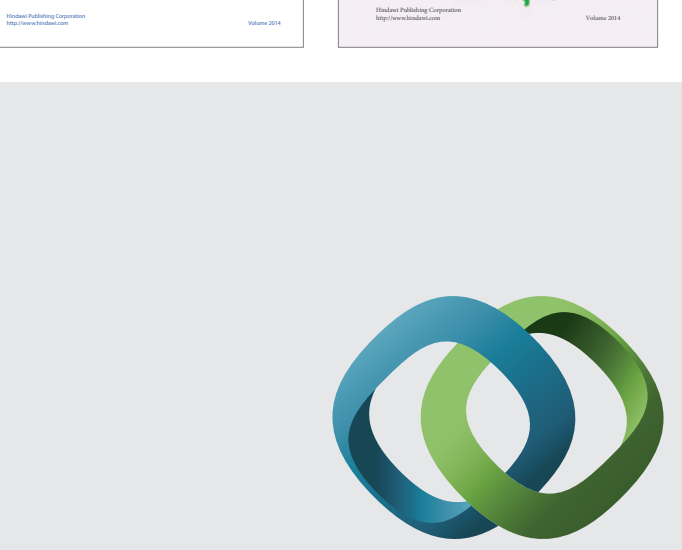

\section{Hindawi}

Submit your manuscripts at

http://www.hindawi.com
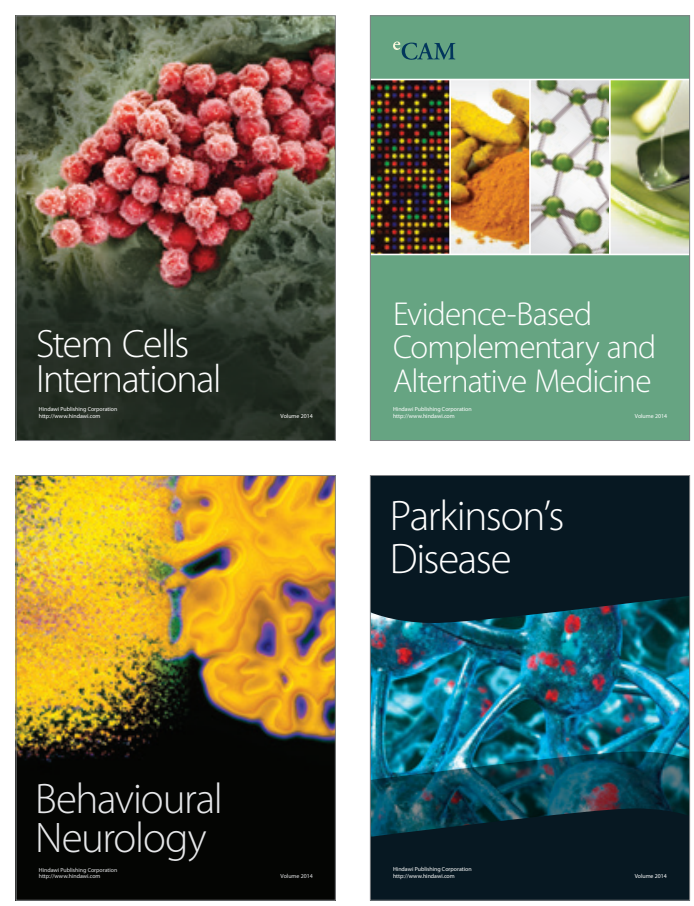

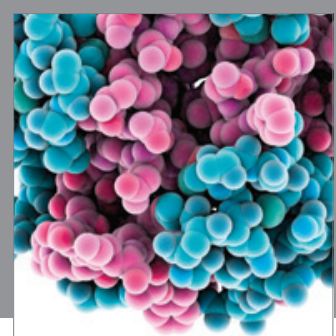

Journal of
Diabetes Research

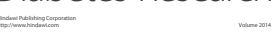

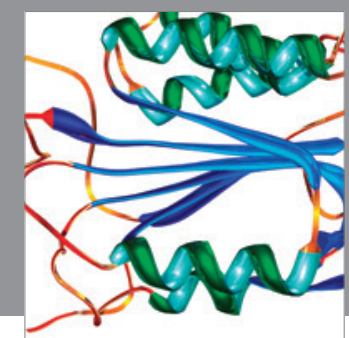

Disease Markers
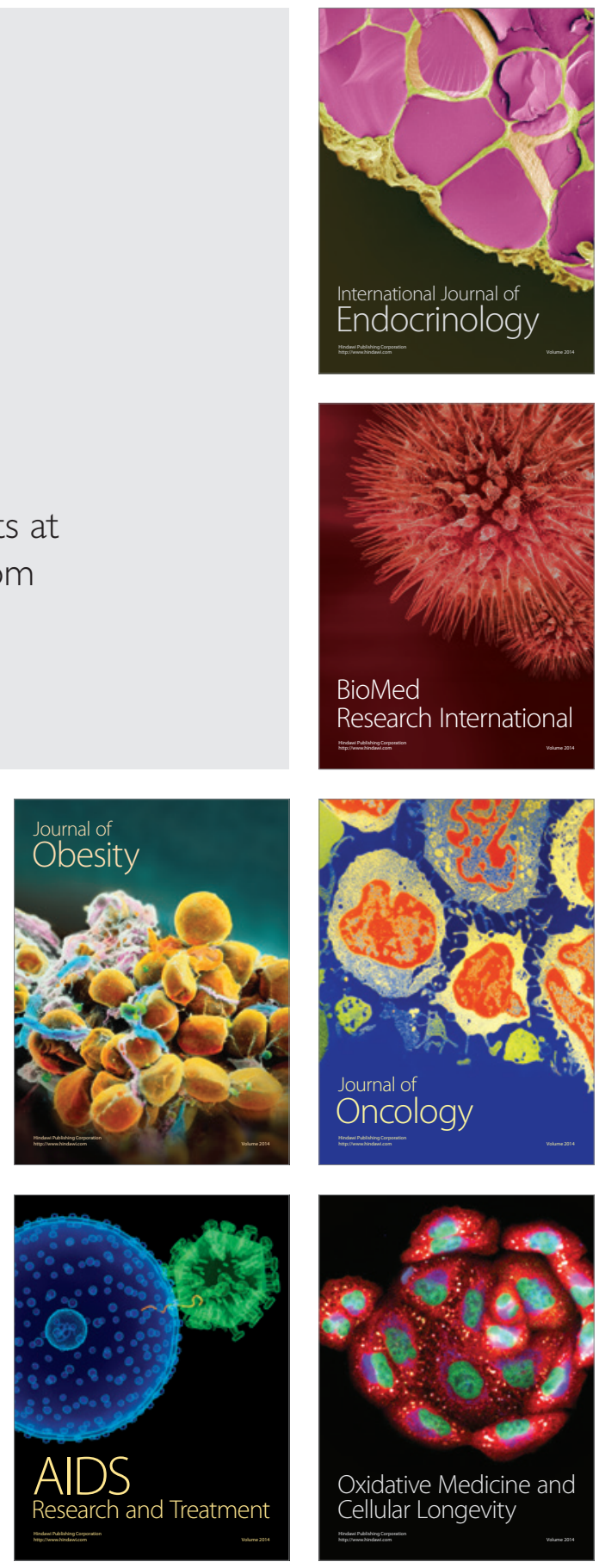